\title{
The Management of Nanotechnology:
}

\section{An Empirical Study of Technology Linkages and Competencies}

\begin{abstract}
The objective of the present research is to explore and analyse the dynamics of nano-technology, focusing on technological development trends, linkages and the profile of competencies. For this, this study maps key technologies and their interrelationships and linkages among inventors; identifies emerging and mature technologies and their application fields; and investigates the revealed technological advantages of leading nation states. In this study, a tech-mining method was used to gather the data, which was subsequently analysed with the Thomson Data Analyser (TDA). A comparative analysis of commercially promising nanotechnology sub-categories is also presented so that governments, universities and private sector companies can benefit from these research findings. The results show that nanotechnology applications in the semiconductor and polymer fields are relatively mature, while carbon nanotube applications appear to be very promising, and are applicable to various sectors. The research also shows the importance of internal linkages to the success of an organisation in the nanotechnology field. However, academic researchers should focus on the requirements of industry, as the new inventions are linked with the needs of large organisations. The findings indicate that the US maintains its position in the Technology pole with high share and high RTA revealing its strong competitiveness. The nano-technological competencies in Japan have been losing strength and it has been falling behind in recent years. A similar trend was observed to the European players, excluding Russia. Asian players such as South Korea and China appear to be the most likely contenders for catching-up with the US. This paper contributes to the literature of management of technology and innovation by providing an improved analytical approach to nanotechnological dynamics and offers a useful insight for academic and research practitioners for forming science and technology policies in the nanotechnology fields.
\end{abstract}

Keywords: empirical study; nanotechnology; linkages; competencies; patents; themescape mapping; revealed technological advantages

\section{Introduction}

Nanotechnology is still a growing area and is considered to be an emerging technology (Bozeman et al. 2007; Linton and Walsh 2008; Islam and Miyazaki 2009). It is widely accepted that patent documents provide a valuable resource for analysing a technological field. Currently, the demand for new inventions enhances increasing number of patents generation. However, in emerging 
technologies this may not be the case as the demand may needs to be created or the process needs to be supported by other actors so that technology diffusion is efficient. Technological and scientific developments have created novel movements of innovation, particularly in the nanotechnology field. For example, the patent classifications for nanotechnology were only introduced from 2004 and are still in their development stage (ETC Group 2005). By exploring the changes in a particular patent data, it is possible to evaluate many aspects of technological change. Quantitative analysis on patents is used as measurement for the results of invention and innovation related activities. There are plenty of patent studies that focus on the association between technological advances and economic progress (Greif 1992, Ma et al. 2009, Sorek 2011, Hidalgo et al. 2012), and there are some studies which focus on the research and innovation developments in both a national and a global context (Abraham and Moitra 2001, Encaoua et al. 2006, Faber and Hesen 2004, Wu and Lee 2007). There is other research that has assessed the stage of technology development in a particular sector by analysing patent statistics from a corporate point of view (Bachmann 1998, Trappey et al. 2011, Tseng 2011).

Bibliometric quantification is an effective way to show the emergence and development of a new technology (Braun et al 1997). Over the past few years, several attempts have been made to study nanoscience and technology management (for example, three journals called Research Policy, Technovation and Technological Forecasting \& Social Change were published their special issues on nanotechnology). The progress of nanotechnology patenting activity, technological competencies, innovations and industry is changing fast, as nanotechnology is a highly dynamic emerging field. Considering similar methodological approach and similar field by other authors, there are various studies that follow bibliometric studies for patent documents and academic publications. Porter and Youtie (2009) looked at nanotechnology positions in relation to other disciplines by considering its multidisciplinary nature. Another similar work was conducted by Miyazaki and Islam (2007), focusing on cross-country comparisons, actors and institutions by using similar quantitative methods (bibliometrics and tech mining) to understand the sectorial innovation systems in nanotechnology from a global perspective. Shapira et al. (2011) focused on an overview of corporate entry into nanotechnology through patents and publications and nanotechnology innovation factors in the shift to commercialization. It is also observed that the influence of cross-border international invention linkages suggests that national innovation policies need to be open and international in orientation. Huang et al. (2003) also completed similar work by presenting a longitudinal patent analysis on nanotechnology patents between 1976 and 2002. Their work included content map analysis and citation network analysis by obtaining the required data from individual countries, institutions and technology fields.

The study of Ma and Lee (2008) is similar to this paper in that it examined the pattern of international linkages amongst countries in inventive activities by using patent assignee information for the period between 1980 and 2005. Another similar work completed by Petruzzelli (2011) attempted to show 
whether specific technological and relational attributes affect the relevance of linkages between academia and industry. This paper put forward various hypotheses about the effect of three relevant factors, which are technological relatedness, prior collaboration ties, and geographical distance, on a sample of 796 university and industry joint patents to see their effect on joint academic and industrial innovation value. Goetze's paper (2010) is another similar work as it combines the method of patent analysis with network analysis techniques by focusing cardiac pacemaker technology and looked at the position of an important inventor within a network in terms of quantity and quality of patents. A related study that used patent citation data was conducted by Cheng (2012) to show that technology diffusion, with the help of patent citation, can be explained by empirical analysis with the help of the Bass diffusion model.

In terms of organizational linkages and patent data analysis, Genet et al (2012) investigated the model of knowledge transfer in the nanotechnology field by comparing it with the models of other emerged technologies, namely biotech and microelectronics. They found that the nanotechnology transfer model is very different from other fields when considering the role of companies within their respective sectors. Beaudry and Schiffauerovac's (2012) study examined the effect of collaboration and co-ownership networks of Canadian nanotechnology inventors on patent quality in terms of four factors: the presence of highly central inventors, the presence of star inventors, repeated collaboration and international collaboration. Their results show that central and star inventors who have positive and repeated collaborations have a negative impact on patent quality. Guan and Zhao (2012) in their research explored patent value based on complex network analysis in the nano-biopharmaceuticals area. This study examined the collaboration between university and industry networks at organizational level. Lee et al (2009) proposed using patent data to analyse four modules they termed monitoring, collaboration, diversification and benchmarking. This paper used various analyses involving text-mining, network analysis, citation analysis and index analysis. As a result, they present four different maps: the actor-similarity map, the actor-relations map, the technology-industry map, and the technology-affinity map to extract strategic information from patent data.

A review of the previous literature indicated there are certain limitations to existing research. These limitations can be divided into those to do with the methodology used and the research itself. In terms of methodology, previous studies used a different patent data collection method. Huang et al. (2011) categorised lexical and patent classification queries by analysing related methodological studies. Porter et al. (2008), Mogoutov and Kahane (2007) and other similar studies often follow lexical queries to gather all patents with nano terms but excluding those patents that have nonrelated nano terms such as 'nanosecond'. Details of this type of search query limitations are explained in the methodology section. Given the limitations and drawbacks of the above approaches, our method uses a combination of the two, as we use both patent classifications and lexical queries. The reason why both approaches are utilised is because as is mentioned in Scheu et al.'s (2006) study, only using 
patent codes has a weakness in that unrelated patents appear in the patent data due to their wrong classification. This paper increases the efficiency of nanotechnology patent analysis as a more reliable patent search query is used. A limited number of studies have focused on technology linkages and sub-domains of nanotechnology. As Nanotechnology is a multidisciplinary field, it is thought that academic and industrial focii may differ due to their research nature and organisational needs. Secondly, there are few studies where organisations are broken down into academic and industrial actors to differentiate their involvement in the nanotechnology field.

Our study differs from previous ones as it looks at the actors' focii in sub-categories of the nanotechnology field. The focus of this work is to examine the linkages between technologies by using patent documents rather than citation or organisational linkages. Patent abstracts and patent codes are a better source of data for this study as it is possible to capture actual technological linkages, while citation analysis is a more appropriate method for presenting knowledge flow between actors. Focusing on types of linkage introduces a different level of analysis in this kind of patent study, and this could introduce different outcomes for technology management specialists and patent analysts. This study looks at academic, industrial and inventors involvement for each country to increase its depth. Existing studies lack the degree of investigation of this study of nano-technological dynamics, and we think it should make a worthy contribution to the literature concerning the acquisition of nanoknowledge and its exploitation in the field of management of innovation, science and technology. The objective of the present research is to explore and analyse the technology development trends, linkages of tech-domains, patent clusters and the profiles of nanotechnology competencies. This study maps the interrelationships among key technologies and top inventors; identifies emerging and mature technology fields and their application domains; and investigates particluar nations' revealed technological advantages. In addition, a comparative analysis is presented so that the research and academic practitioners, governments, universities, and private sector companies can benefit from these research findings.

Given the nanotechnology innovation system, it is to be expected that tech-domains of nanotechnology will be linked to each other at various levels. This paper aims to answer the following questions; how nanotechnology's technological linkages are shaped due to its multidisciplinary nature; where linkages between technological domains occur and their causes; and how the trend of technology competencies is changing with respect to the leading nations' involvement in nanotechnology.

\section{Theoretical Framework}

This study looks at the systems of innovation theory in terms of the interactions of various actors in technology development and diffusion within this system. The innovation system comprises the 
linkages and flow of information among actors such as inventors and organisations in terms of innovative processes (Lundvall 1992, Liu and White 2001, Doloreux 2002, Yim and Kang 2008 and, Guan and Chen 2012). An innovation system model aims to describe the processes and interactions between the actors to facilitate the value chain from the beginning of an invention to a commercialised innovation stage (Yim and Kang 2008, Roper et al. 2008). The system of innovation concept has gained the attention of a growing number of researchers to explain innovation in terms of actors, processes and flow of information. Various studies have been published in the literature, including national systems of innovation ((Lundvall 1992, Nelson 1993 and Freeman 1995), regional innovation systems (Cooke and Morgan 1994, 1998), sectoral systems of innovation (Malerba 2004), technological innovation systems (Carlson and Stankiewicz 1991) and functions in innovation systems (Johnson 1998). Looking at these different models, the notion common to all of them is to explain how an innovation system develops, diffuses and utilises innovations within different contexts. The innovation system model differs in terms of the concepts used and the actors identified and emphasised. Another model looking at the relationships between actors within an innovation system is the triple helix model that presents manifold mutual relationships at various stages of knowledge capitalization processes (Leydesdorff and Meyer 2003).

One of the most important aspects in an innovation process are the linkages among knowledge and technologies, actors and networks, and institutions (Malerba 2004). In an innovation system, collaboration networks can take different forms, for example that of an industry cluster (CamarinhaMatos and Afsarmanesh 2006). Industry clusters are the primary stage and comprise a group of companies which are characteristically located in the same region and form part of a common industry (Camarinha-Matos and Afsarmanesh 2006). Due to regional and sectoral bonds, an industrial cluster aims to escalate the overall competitiveness of its members in their region and also tries to expand it to other regions. Some of the benefits of being a part of such a collaborative network can be sharing information and expertise such as buyer/supplier externalities, or making use of common resources such as technological tools, or providing support to each other when various business opportunities/challenges arise. Patents can be a part of this kind of collaboration, as sometimes patents are used as barriers. However, patents may also be the starting point of an industry cluster in terms of spin-offs and academic institutions. Nanotechnology can be classified as a science-based cluster (OECD 1997) which is highly R\&D-and patent-focused and is likely to have a close relationship with the public research sector (i.e. universities, government research bodies etc.) This is due to their requirement for basic research and so it is essential for the public research sector to become involved for there to be an effective innovation structure.

There are various models that analyse linkages of actors within an SI, for example the triple helix model, the TEN model, and network models. These different models are examined in this paper to gain information about the structure or types of linkages within an SI. The Triple Helix concept 
comprises a model for collaborative relationships between three major institutional spheres that comprise universities, industry and government, in which innovation is an outcome of interaction. This model presents manifold mutual relationships at various stages of the knowledge capitalization process (Leydesdorff and Meyer 2003). There are three main different actors within this model and these actors may or may not be linked effectively in terms of patenting activities. Through patent analysis, it may not be possible to see the linkages between government and other actors, as the fund providers cannot be identified through patent analysis. However, it is possible to identify the linkages between academia and industry and relate this information to the model. This model can be used to understand insights of interactions between two spheres, which are academia and industry.

Another framework that illustrates the roles and linkages of actors within an innovation system is the Techno-Economic Network (TEN) as illustrated in Figure 2 (Callon and Bell 1991, Islam and Miyazaki 2009). The TEN framework is a useful framework to analyse the systems of innovation in a comprehensive manner for a chosen sector (Callon and Bell 1991, Islam and Miyazaki 2009). The TEN concept is an effective framework when the aim is to study an innovation system at a large scale, to consider its complexity. There are four different poles within the TEN framework and it has been organized around three major poles that are technology, science, and market. Another minor pole that is presented within this system is the Finance Pole, due to its indirect players or innovation links. Each of these poles is categorized by the type of actors and intermediaries in regard to their duties. Intermediaries vary in terms of tangible and intangible resources for those actors within TEN. Moreover, it shows how the poles are linked to each other in terms of their direct or indirect linkages and also it shows which intermediaries they are linked by, for example the Transfer Pole (between the Science and Technology Poles) and Development Pole (between the Technology and Market Poles). Following this model it should be possible to identify various collaboration mechanisms within a system. Even though the TEN model and the triple helix model illustrate actors and their linkages, these models do not identify collaboration mechanisms in regard to types and formation of networks.

\section{[Insert Figure 1 here]}

Having examined different collaboration methods, the network structures of these linkages should be analysed as well. One can assume there would be multidisciplinary linkages in nanotechnology patenting activities and that there would be technological domains, but it is not clear how the technological linkages in nanotechnology are shaped. Comparing different models and considering previous literature in this field, the proposed model as demonstrated in Figure 2 will be used to examine the nanotechnology field. The proposed model assumes that this field be diffused among different areas as shown in Figure 2. These linkages among technology domains need to be identified. It is also to be expected that there are linkages within the same discipline or across disciplines with 
some particular patents. Moreover, one can assume there will be diffusion in terms of patent usage in some applications as they may require multiple patents from different patent owners.

[Insert Figure 2 here]

\section{Research Design}

The present study applies a tech-mining method, proposed by Porter and Cunningham (2005), which draws heavily a significant impact on the analysis of nanotechnology spectrum. Tech mining analyses relations between actors and technologies within a given innovation system, using specialist keywords, derived from the Nano Science and Technology Institute (NSTI) publications. The subsequent analysis was performed using dedicated tech mining software Thomson Data Analyser (TDA), automating mining and clustering of terms occurring in article abstracts and article descriptors such as authors, affiliations or keywords. In addition to the patent analysis by TDA, another offering of Thomson Innovation called Themescape tool is used. By using Themescape, the key technologies are mapped for all available nanotechnology patents. The analysis of a Themescape map was highly supportive for the findings of this study because it allowed the categorisation of documents containing similar content as they were placed near each other on the map. Moreover, the density of documents can be indicated with tall or small peaks and the distance between peaks sheds light on the relationship between content, as peaks that are located closer to each other have more closely related content than peaks that are located farther away. Contour lines indicate relative document density and by using the tool it is possible to zoom in on a specific area whereby new contours, labels, and documents can be revealed.

The problem with collecting the required nanotechnology related patents is that there are many nanotechnology related patents that include those unnecessary terms. This is due to fact that there are many nano related unnecessary terms and some unrelated patents such as micro level patents are included within the nanotechnology patent category. As a result, there is a possibility of obtaining unrelated patents with the nano-patented inventions. By examining the limitations of the various data search approaches, it was thought that the best nanotechnology patent search practice would be to use all available nanotechnology classifications to gather all the nanotechnology patents such as 977 classified by USPTO, B82 by IPC, Y01N by ECLA and 3C082 by Japanese F-Terms. All irrelevant patents classified within these categories could be eliminated by using Boolean search logic with very broad nanotechnology related terms, such as 'nano*', 'quantum*' and 'fullerene*'. Afterwards, enhanced patent data from DWPI (Derwent Patent Index) is used to exclude patents that appeared more than once in the search results. For the nanotechnology case, the following search terms are used: 
$(\mathrm{AIOE}=(\mathrm{B} 82 *)$ OR FIC=(B82*) OR UCC=(977*) $)$ AND ALLD=(nano* OR quantum* OR Qdot OR Qubit OR atom* OR probe OR epitax* OR fullerene* OR thin ADJ wire* OR thin ADJ film* OR buckyball* OR scanning ADJ microscope* OR tunnelling ADJ microscope* OR scanning ADJ electron* OR bionano* OR bio-nano* OR gCNT* OR Peapod* OR CSCNT* OR CNT* OR g-CNT* OR colloidal ADJ crystal*)

The validity and reliability of this patent collection method is illustrated in Figure 3. This figure shows why collecting the required patents in the nanotechnology field is a challenge and how the required patents are collected in this paper compared to previous studies mentioned earlier. There are four different "nano"-related patent categories introduced. The first of them comprises those nanotech-related patents that are required to be collected. The second type of patents that are mentioned in the Figure are those nanotechnology-related patents that include nanotech-related terms but are not really nanotech-related patents. To give an example, there are many documents that mention nanotech related terms such as, "this new material also can be used with nanotubes, nanowires and nanotech," but the patent is not really related to nanotech patents. This group is very difficult to eliminate from the patent data as it contains cases categorized under nanotechnology related categories, so the only way of eliminating these patents is to examine patents individually. The third group are those patents that include "nano" terms but are not nanotechnology-related patents, such as nanosecond or the iPod nano. Patents in this group are easy to eliminate using this patent collection method as they are using nanotechnology classifications and nanotech terms means they are double-checked. The last patent type comprises those patents that are classified under the nanotechnology category such as B82 or 977, but are not nanotechnology-related patents. There are many micro structural related patents under these categories and the main problem with them is that they are not really nanotechnology-related patents, given the requirements and the definition of the nanotechnology field, However, this issue is improving as the B81 (micro structural technology) classification is now being used more carefully and there are assigned teams that work on this issue. The three clusters are presented in Figure 3. If a list of "nano" terms is used to collect required patents, there is a big possibility that unrelated patents will be collected. Moreover, if one attempts to exclude unnecessary patents by utilising such terms as "-nanosecond*", there is a possibility that required patents also will be excluded, as there is a significant number of patent documents which mention nanotechnology related terms and nanoseconds. It can be argued that there is a possibility of having non-nanotech related patents or missing nanotech related patents in the collected data due to the issues stated above. However, this patent search query is an effective method in terms of higher reliability of patent data gathering when compared to other methods. Moreover, even if the data were optimized further, results would not be noticeably different given the type of analysis being followed.

[Insert Figure 3 here] 
As a result 49544 individual nanotechnology patents were obtained for the period from of 1970-2012. The obtained results were imported into the Thomson Data Analyser (TDA) to validate the results further. The duplicate results were eliminated and variations of company, inventor, institutes and university names were unified where they appeared as separate patent assignees. After the dataset was cleaned and prepared, various functions were utilized using the same TDA tool to generate the required analysis. The outline of research design is shown in Table 1. In general, gathering the valid patent data, efficient analysis of large data sets, and handling and interpreting the outcomes of the analysis is crucial for the accuracy of the results.

[Insert Table 1 here]

\section{Results}

\subsection{Changing Trends in Nanotechnology}

In this section a general overview of nanotechnology development trends is presented with regard to patenting activity. In general, the progress of nanotechnology patenting appears to be very promising for commercial activities. There are 73,096 inventors, 29,884 organisations and 68 countries involved in nanotechnology patent generation. There are 49,543 patented inventions, of which 29,217 are owned by corporations, 10,787 by academic organisations (universities and other institutions), 14,164 by inventors and 1,887 by governments. The total number is higher than the actual patent number because there are a number of shared patents among different organisations (see Table 2). There are 1784 patents that are shared by corporate and academic organisations. As shown in Figure 4, the peak period appears to be between 2001 and 2009, which accounts for almost 70\% of overall nanotechnology patents (all the patenting activity for 2010 and 2011 cannot be presented as not all the patents have yet been granted). There are three different stages that can be highlighted from the patent activity in the nanotechnology field. The first of these is the stage where the nanotechnology patents started with the patents that focused on the research and development of the nanotechnology field. In the development stage, there was not a notably rapid increase. In the growth stage, the rapid increase in number of patents appeared and in this stage the area of nanotechnology expanded with the addition of various nano-materials. In the stage that is called the peak point, nanotechnology patenting activity was at its highest level, and at this stage the various products and supplements were introduced in the nanotechnology field.

\section{[Insert Figure 4 here]}

[Insert Table 2 here]

Since the technology diffusion period of many technologies is becoming progressively shorter due to strong networks, systematic approaches and developed information and communication technologies, 
the increased number of nano-patents may lead to the commercialisation stage in the near future. Additionally, the availability of almost fifty thousand granted nano-patents within the maximum patent grant period of twenty years suggests the highly commercialised era of nanotechnology is imminent. However, as mentioned by various analysts (Kronz 1980, Suzuki 2011, Ernst et al. 2012), only a few patents have commercial viability, so only some of these patents will be turned into innovative products. There are many taxonomical approaches (Meyer 2001, Kostoff et al. 2006, Kostoff et al. 2007, Cunningham 2011) for identifying how nanotechnology expands its own terms and categories. Figure 5 shows that new knowledge and technology trends are rapidly developing within the nanotechnology field. Accordingly, there are new patents that do not match previous nanotechnology patent categories and are categorized as extensions of previous patents, or categorized in completely different nanotechnology sections. In general, this is due to the highly dispersive characteristics of nanotechnology, but in particular, two aspects can be identified. The first is that much fundamental research in nanotechnology has some applicability under various different technologies and so even though the core technology is the same, it has to be patented differently. The second is that there are radically new nanotechnology inventions, which are mainly at the fundamental research level. It appears to be this new fundamental research, which plays a key role, is cited in various applications and is generating new nanotech patent terms.

[Insert Figure 5 here]

\subsection{Involvement of Academia, Industry and Sole Inventors in Nanotechnology}

Previous studies fail to investigate nanotechnology related developments by examining them in respect to their academic, industrial or sole inventor provenance. The benefit of this section of the study is to show where academia's, industry's or inventors' foci are in terms of technological domains. Moreover, this section shows the involvement of these three categories in terms of their country base and how academic and industrial involvement differs from one country to another. Each organisation studied was categorized as academic, industrial or sole inventor and these categories are analysed by following matrix analyses in terms of the country of origin and patent categories.

Looking at Table 3, it can be seen how academic, industrial and sole inventors' involvement differs according to the country concerned. In the US, Japan, Germany and the UK, there is a greater involvement of corporate actors than academic organisations. This is mainly due to the presence of large corporate players in these regions and also large players' interest in patenting their technologies in these regions. Another reason why these countries appear to have business-driven patenting activity is because the electronics industry is the one with the greatest interest in this field, and many large electronics players in this field are based in these regions, such as IBM in the US and NEC in Japan. 
Academia's involvement in China, Russia and Taiwan appears to be more influential compared to corporate actors, which was not an expected outcome when the nature of their patenting activities is considered. These results are combined with interview analyses to understand why these three countries have higher academic involvement. In China's case, interviews with key experts were conducted and it was found that this is mainly due to the government's funding approach as academia has the greatest funding share and there are few joint funds provided for academia and industry to work together. In addition, analysis of the structure of China's patenting system shows a politically driven patenting system which gives considerable support and motivation to academia to file patents. Patent filing is highly linked to promotion, bonuses and further research grants and patenting is prioritized over publications. Also, looking at individually owned nanotech patents, it appears that the US and China have are at the forefront with this kind of patent ownership.

[Insert Table 3 here]

In this section, patent classifications are used to examine academic, corporate and inventor involvement and to discover in which technologies they are highly concentrated. Table 4 shows that while the significant patent share is held by industrial players, as is to be expected,, academic involvement is still noteworthy. In the fields of General Chemicals (E) (), B (Pharmaceuticals), S (Instrumentation, Measuring and Testing) and D (Food, Detergents, Water Treatment and Biotechnology) academic involvement is almost at the same level as corporate players..

[Insert Table 4 here]

\subsection{Linkages through Inventors}

An alternative way of looking at the growth of a technology sector is to look at the number of inventors involved in that particular field such as nanotechnology. As shown in Figure 6, there has been a significant increase in the number of new inventors which has been more than double the number of existing inventors for every year since the mid-80s. The highest number of newly participating inventors was in 2008 at 7,696 inventors. With regard to the period between 2005 and 2009 , this figure shows that there were between 3000+ and nearly 8000 new inventors in the nanotechnology field. This is crucial for an emerging technology to develop further. The highest number of previous inventors was 4415 in 2008. However, comparing this figure with the previous ones, it can be seen there is a positive relationship between growth in the nanotechnology field and intense involvement of new inventors.

\section{[Insert Figure 6 here]}

The analysis of inventors' patenting activity shows the internal linkages within an organisation (see Table 5). The leading inventor in a number of nanotechnology fields appears to be Yang Mengjun in view of his 908 individual nanotechnology patents. It is notable that there has not been a single 
collaboration between Yang Mengjun and other inventors, and also that all the patents granted to him were registered between 2000 and 2001. His nanotechnology research focuses on nano-foods, specifically on ancient Chinese medicinal herbs which he reduces to the nanoscale to increase the efficiency of the formulation. All of his patents have been granted by the Chinese Patent and Trademark Office. Yang Mengjun's inventions have limited applicability to other technologies and they are not cited by other scientists. This characterises the patenting trends in China that indicates the importance of patent quantity over patent quality.

A significant level of linkage can be seen between Hon Hai Precision (Foxconn) inventors. This points out to one of the factors that have enabled Foxconn to become one of the leading organisations in the nanotechnology field. Foxconn inventors have among the highest profiles in nano patenting activity and there is a huge linkage between internal and external inventors. This suggests that Foxconn's innovation system is very efficient in terms of collaboration in patenting activity because Fan Shou Shan, who is the Director of Tsinghua-Foxconn Nanotechnology Centre, holds the second highest number of patents in the nanotechnology field, most of his patents being linked internally with Tsinghua University and co-owned by Foxconn. These kinds of linkages are crucial for the commercialisation of nanotechnology, as the greater the linkage between academics and corporations, the greater the possibility that new inventions can take place in products/services.

Table 5 also shows the importance of internal linkages within an organisation. The collaborative research activities of Fan Shou Shan, Jiang Kai Li and Liu Liang are a great example that shows how effective internal linkages are to the success of their organisation, giving it a dominant position in the nanotechnology field. The large investment of Foxconn is another important factor as when large private organisations participate in innovation networks, it strengthens the bonds between internal and external collaborations. The diffusion of nanotechnology into the commercialised era will be faster if academic researchers focus on the requirements of industry, as the new inventions are linked with the needs of a large organisation such as Foxconn. This analysis also proves the possibility of having a dominant position in a short time period such as 10 years (as shown in Table 5) if all the actors within an emerging innovation system works efficiently and there is a strong linkage between private-public organisations, as appeared in the Foxconn case.

[Insert Table 5 here]

\subsection{Emerging Technology Fields in Nanotechnology}

This section provides snapshots to see the mature and the emerging technologies in the nanotechnology field, as shown in Table 6. Some of the mature technologies are V08-A04A (semiconductor laser), U12-E01B2 (Semiconductor body with quantum wire, wells, super-lattices) and U11-C01J6 (Semiconductor materials and processing, strained layers and their manufacture). 
Accordingly, it is reasonable to assume that nanotechnology inventions with the semiconductor materials and applications are relatively common and mature compared to other nanotechnologies. Looking at the emerging technologies, A12-W14 (polymer applications with nanotechnology) appears to be the most rapidly developing technology in this field as in 2004 there were only 72 patent records while this increased to 1,283 records in the peak year, 2008 (see Figure 7). Moreover, almost 35\% of the patents appear to have been granted in the last 3 years. Another emerging technology within the nanotechnology field is U11-A14 (nano-structural materials) for which $23 \%$ of patents have been granted in the last 3 years. The peak point for U11-A14 was in 2006 with 393 patent records, while in 2003 there were only 47 patent records. Between 2006 and 2009, there were over 300 patents granted for nano-structural materials each year.

Nano-structural materials have great applicability in the market. These materials include atomic clusters, layered films, filamentary structures, and bulk nanostructured materials, which have applicability in synthesis and processing of powders and films, thermal spray processing and gas reactive applications and more. Another technology within the nanotechnology field that has shown promising growth in recent years is E05-U03 (carbon nanotubes). Carbon nanotubes (CNTs) had only 4 patents in 2000, but this gradually increased to 417 patents in its peak year of 2004. Between 2004 and 2009, the number of patents in CNT field was always higher than 350 patents per year. The rapid increase in CNT patent documents is due to the recognized importance of this nanostructure in a very broad field. It is a very promising nanostructure and it has the potential to be one of the key nanostructures in the future. For example, MOSFETs, regarded as the key transistors for today's electronics applications and it plays a key part in various devices. It is predicted in many studies that semiconducting CNTs will replace MOSFETs, and this new transistor, called field effect transistors or CNTFETs. This is because of CNTFETs' impressive characteristics over traditional transistors such as less power requirements, miniaturized size and strong material characteristics. Also, there were some technologies that had a notable decline in the number of granted patents, for example U12B03F2 (nanostructural systems for devices and thick/thin film and organic semiconductor devices) and U11-C01J6 (heterojunction, superlattice structures, quantum wells, wires in semiconductor device manufacture) between 2005 and 2009.

[Insert Table 6 here]

[Insert Figure 7 here]

\subsection{Mapping Key Technologies and their Application Fields}

In this section, the key technology terms are mapped for all the nanotechnology patents available. The Figure 6 was formed by using the Themescape tool, offered by Thomson Innovation. The analysis of a Themescape map is useful because it allows viewers to see the numbers of documents containing 
similar content as they are drawn near each other on the map. Moreover, the density of documents is indicated topographically and the distance between peaks throws light on the relationship between content as peaks that are located closer to each other have more closely related content than peaks that are located farther away.

Considering the multidisciplinary nature of nanotechnology and technological domains, Figure 8 presents how the technological linkages in the nanotechnology field are formed. The proposed model assumed that there were linkages between patents in terms of their technological domains and their fields and that there would be diffusion from one to the other. The figure shows technological linkages between patenting clusters, and the volume of these linked patents can be seen by the contour height between each technological field. However, Figure 8 does not make explain why these particular linkages appear between technologies and what the sources of these technologies are. To find that out, analysis of each technological linkage is required. The following sections explain why these particular tech-linkages appear and why they are important in their respective industries.

As was shown in Figure 8, it could be seen that various applications of nanotechnology in semiconductors, polymers and carbon nanotubes were the dominant fields. This time, the relationship between these dominant fields can be seen in the Themescape mapping. Nanotubes, polymers and semiconductor terms appear together in one of the highest peaks, which indicate the high number of content availability within in each technology and the strong relationship between them. It could be predicted that nanotubes, semiconductors and polymers may have the potential to be the key materials under the nanotechnology umbrella in various sectors and most importantly in the electronics field. In the electronics field, there are many researchers interested in the relationship between carbon nanotubes and polymer semiconductors as they increase the efficiency of materials in many ways such as increasing the mobility and reliability of electrical properties of circuits. It has been found that random arrays of nanotubes can form semiconducting and conducting networks. Commonly, singlewalled carbon nanotubes are used with polymer semiconductors in this kind of application. Some of the applicability of these materials in the industry is in display technologies, storage devices, sensors and printed electronics. With regard to the bottom-up approach of nanotechnology, this type of material increases the environmental and operational reliability of displays and leads to simplicity in device fabrication and competitiveness in device performance for printed electronics. With regard to top-down approaches, it leads to innovative products such as bendable display screens, stretchable electronics and circuits that are printed on plastic. At present, the scientific endeavour is to make carbon nanotubes a practical option for transistors in microprocessors and other electronics. This is one of the reasons why large establishments in the electronics industry such as Samsung, Hon Hai Precision (Foxconn) and NEC are seriously investing in these nanomaterials, as the patents granted in this area are likely to be one of the key competitive advantages in the future. 
Other intense interest in nanomaterial is with regard to washing powders with dimensions of 1 to 100 $\mathrm{nm}$ that can be created. Nano washing powder has high detergency, involves simple and safe production processes and low cost, and may be used to replace available no-phosphate washing powder produced with zeolite. Some research has focused on nano-powders applicability with Titanium Oxide (TiO2). One of their key research areas is the dispersion of nanoparticles in relation to the suspension of nanoparticles in water. The purpose of this kind of research is to invent stable metal oxide nanoparticles ( $\mathrm{TiO} 2, \mathrm{ZnO}, \mathrm{SiO} 2)$ in aqueous solutions. The commercial application of these nanoparticles has increased in recent years due to their unique physical and chemical properties. Some of these applications in the industry are with UV-resistant materials, nano-coatings, selfcleaning materials, cosmetic products and waste water purification.

In relation to relative applicability of nanostructures, it can be seen that nanowires and carbon nanotubes have conjoint applicability. We also looked at why nanotubes, nanowires and semiconductors appear together on the Themescape map. Nanowires are wires at nanoscale and consequently are very thin structures. Scientists hope to use them to build tiny transistors for computer chips and other electronic devices. The characteristics of nanowires vary depending on the element that is used and they can have the properties of an insulator (e.g., SiO2, TiO2), a semiconductor (e.g., $\mathrm{Si}, \mathrm{InP}, \mathrm{GaN}$ ) or a metal (e.g., Ni, Pt, Au). Metallic nanowires carry electric charges very well, insulator nanowires do not carry an electric charge and semiconductor nanowires are amongst the two other types of nanowires that carry a charge under the right circumstances. By arranging semiconductor wires in the right configuration, it is possible to create nanotransistors which can act as switches or amplifiers. Also, they can be used as logic gates (AND, OR and NOT gates) in semiconductor nanowire crossings. The nanostructures that can be made from nanowires can be used to build a nanocircuit with the help of carbon nanotubes, for example with nanotube-based transistors (CNTFET). Yet again, this is a field that large electronics companies are conducting research into and attempting to gain key patents.

[Insert Figure 8 here]

\subsection{Profile of the Competencies - A RTA Analysis}

In this section, a profile of the nano-technological competencies is mapped for all the nanotechnology patents available. The data were converted to calculate regional advantages in nanotechnology as it seems better to compare on a relative rather than on an absolute basis. The transformation has widely adopted in recent works on comparative technological development at both country and sector level by using a tool called Revealed Technological Advantage (Cantwell, 1993; Patel and Pavitt 1997). To view a comparative dynamics on nanotechnology competencies, we compare the most advanced players in nanotechnology (similar studies were done by Islam and Miyazaki on nanotech research 
domains and by Kumaresan and Miyazaki on robotics). However, Miyazaki (1995) conducted a study on optoelectronics-related competence building in European \& Japanese firms using a similar approach. The dynamic changes in the comparative positions of different regions are identified for categorizing the technological competencies of firms in the Science and Technology poles. As illustrated in Figure 9, the X-axis represents the share of patent activities in the Technology pole and the Y-axis indicates the Revealed Technology Advantage (RTA) of countries to measure the comparative advantage of scientific and technological strength.

The RTA-index has been used as an approximation of the advantages in certain technology fields, consists of the ratio of the number of patents of a country in a particular technological sub-domain, divided by the total number of patents in this sub-domain, and the number of patents of the country under study in the whole field, divided by the total number of patents in the field $\mathrm{RTA}=(\mathrm{Pij} / \mathrm{PiPij}) /(\mathrm{PjPij} / \mathrm{PijPij}) ; \mathrm{A}$ value above 1 indicates relative strength and a value less than 1 indicates relative weakness. The regions of high share and high RTA can be interpreted as countries having relatively strong share in the Technology pole (i.e. relative importance to competencies in nanotechnology) and having distinctive advantage nationally. The region of low share and low RTA reveals countries allocating relatively less resources to technology or science and having less distinctive advantage nationally. It is to be noted that the value of the benchmark share in the X-axis is difficult to identify and varies depending on various dimensions such as the countries or region considered, innovation process analysed, national requirements, etc. In this case, a break-even share is chosen in order to accommodate all countries in such a way that a proper comparison of their technology or innovation performance be made. Therefore, in this analysis, what matters is the direction of movement and comparative positions rather than absolute positions.

Figure 9 illustrates the relative comparison of strength in technological competencies for the advanced players in nanotechnology. The result indicates that the US maintains its position in nanotechnology pole in the high share and high RTA zone in all periods (above $40 \%$ patent share) revealing their strong competitiveness in the relevant technology field. On the other hand, Japanese position in the technology competencies moved from a high share and high RTA zone in 1900-1994 period towards a significant low share and low RTA zone in 2004-2009 period. The Japanese contribution in nanotechnology field was substantial (41\%), comparable to the US, in the early 1990s and then it slowly get down to around $25 \%$ in $2005-2009$. This indicates that relative to other regions, the nanotechnological competencies in Japan has been losing strength in mid 1990s and falling behind in recent years. Similar trend was observed in the case of top European player (e.g., Germany and UK). The decline in RTA may due to the entry of other Asian countries into nanotechnology activities.

Alternatively, Asian countries' trajectory is moving in the opposite direction to Japan and the EU. The top regional players have exponentially picked up their position in the early 2000 s, which may due to 
their actors' initiatives and policies to push nanotechnology into potential sectors. Asian countries such as South Korea and China including Russia have gained substantial strength in nanotechnological competencies in 2004-2009 period. The finding is an indicative that the Asian giants' nanotechnology competencies have focused and directed towards nanomaterials production and their application into nanotechnology-based products, i.e. nano-knowledge may apply into all sectors and emphasis will be given to nanotechnology $R \& D$ and their potential applications. It seems China to be the most likely contender for catching-up with advanced countries. Including public infrastructures several grassroots organizations are sprouting up to take advantage of nanotechnology field. It is very interesting to see that the direction of the Asian players are high exponential in nature in their nanotechnology pole. The analysis reveals the learning patterns of technology and innovation structure for the technology pole in a comparative evolutionary perspective.

[Insert Figure 9 here]

\section{Discussion and Implications}

The motivation to conduct this research is the increasing pace of nanotechnology development and diffusion worldwide. In this paper, the main output is mapping of nano-technological dynamics focusing the technological trends and competencies, their interrelations, and the comparison of regional strengths and weaknesses. An interesting outcome of this research was to see the changing trend of countries' involvement in nanotechnology. Asian players in the last years had huge involvement in this area. It appears that South Korea and China are now catching up with Japan and close to the US in terms of RTA analysis. The analysis of the nanotechnology-patenting linkages presented novel results. China presented a great illustration of effective linkages in patenting activity between inventors of Tsinghua University and Hon Hai Precision (Foxconn).

Analysis of the technological linkages of patent documents has given highly informative results in terms of interrelationships within the nanotechnology field in comparison to previous studies, which mainly focus on citation analysis and co-ownership of patent documents. We believe this study has greater validity than other studies due to its large sample size and greater accuracy of its patent search query. The study can be considered to be reliable as technological linkages are checked with multiple sources. This study uses a Themescape analysis to show technological linkages under the nanotechnology umbrella. In addition, it presents changing trends in terms of sub-categories of nanotechnology, for example which technologies are emerging and which ones are in decline.

Involvement of inventors is examined to see if nanotechnology is expanding due to the entry of a higher number of inventors or whether the same inventors are behind the noteworthy increase in nanopatent documents. This study shows that there has been a significant involvement of new scientists in this field starting from the early 2000s, and that this is related to many causal factors such as Bill 
Clinton's influence and speech at the National Nanotechnology Initiative (NNI) in early 2000, or the increased funding for nanotechnology starting from 2003 in the US. The data presented bythis study will be useful to other scholars wishing to establish causal relationships in the field of nanotechnology.

This paper also looked at the key emerging technologies. There are three different areas identified that have the greatest potential for commercialisation. It was found that semiconductor applications, polymer applications, carbon nanotubes and medicine were fields where nanotechnology is used the most. With regard to the usage of semiconductors, polymers and CNTs, the electronics industry appears to have the strongest link with nanotechnology. By using the Themescape tool, specific nanotechnology related terms were analysed to see their linkage, their intensity and their various usages. For example, Nanocrystalline semiconductor materials can be used in flash memories that have a wide usage in many electronic devices such as pen drives, memory sticks, MP3 players, PDAs and hybrid hard disks. The significance of nanostructures in semiconductor memories is that this kind of nanomaterial can scale down the switching circuit areas as the thickness of $\mathrm{SiO} 2$ layers cannot be reduced any further. It could be predicted that nanotubes, semiconductors and polymers may have the potential to be the key materials under the nanotechnology umbrella in various sectors and most importantly in the electronics field. This is one of the reasons why large establishments in the electronics industry such as Samsung, Hon Hai Precision (Foxconn) and NEC are seriously investing in these nanomaterials, as the patents granted in this area are likely to be one of the key competitive advantages in the future.

The result shows the regional strengths and weaknesses. To view a comparative dynamics, we have compared relative advantages of EU, the US, and the Asian regions in nanotechnology developments. This indicates that the US maintains its position in the Technology pole with high share and high RTA in all periods revealing their strong competitiveness in the nanotechnology field. On the other hand, Japanese position in the technology competencies moved from a high share and high RTA zone towards a significant low share and low RTA zone in recent years. This indicates that relative to other regions, the nano-technological competencies in Japan started losing strength in mid 1990s and fallen behind in recent years. Similar trend was observed in the case of top European player (e.g., Germany and UK). The decline in RTA may due to the entry of other Asian countries (especially exponential growth of South Korean firms) into nano-technological activities. While China (including Hong Kong) contributes relatively low percentage share in the Technology pole, its distinctive advantage in nanotechnology is still low, but promising in future which is instructive as the emerging giant for nanotechnology.

In regards to the TEN model, networks and clusters within nanotechnology innovation system showed that boundaries of interactions are not limited to the national level and also there are interactions 
between different type of organisations so it is not possible to limit this field into certain sector either. However, it is identified that there is a great weakness within nanotechnology innovation system that the linkage between Science Pole and Market Pole is not strong enough in terms of patenting activities. There were some strong linkages, such as between Foxconn-Tsinghua but these types of linkages were so rare in overall. The weakness in collaboration between the Science, Technology and Market poles may be why the nanotechnology field is not in its highly commercialized stage. Strengthening the linkages between scientific and corporate actors may eliminate many barriers and accelerate the diffusion of nanotechnology in commercial and scientific fields. The implication of this study is the following: 1) The substantial increase in patent generation by Asian organisations to catch-up, especially South Korean and the Chinese region appear to be having a great impact in the nanotechnology field; 2) Evaluation of the competition and the analysis of technological competences profile of countries; 3) Examination of existing and future technologies within the nanotechnology field to see their potential commerciality, linkages of patent classes with various industries and the interconnection of various nanotechnology patents amongst different areas for the technology; 4) Key potential technologies in the nanotechnology include semiconductor and polymer technologies; 5) Active or potentially active organisations should become involved in this field to gain competitive advantage

To take this study further, there are many other relationships that can be looked at within nanotechnology. Future studies could look at different technology domains and their relationships with each other at the national and international levels. As was mentioned above, there are some organisation and inventors that hold a high number of patent documents but the question is whether they are highly influential patents in terms of citations, commercial potential and quality. Interviews and surveys collected from academic and non-academic organisations could be used to gain a more in-depth understanding of the topic. A statistical analysis of the relationships pertaining between commercialised patents and latest granted patents could be done to examine various relationships and forecasts between inventions and innovations.

\section{References}

Abraham B. P., Moitra S. D., 2001. Innovation assessment through patent analysis, Technovation, 21 (4), $245-252$.

Archibugi D. Planta M., 1996. Measuring technological change through patents and innovation surveys, Technovation, 16 (9), 451-468,519.

Bachmann A., 1998. Profiles of corporate technological capabilities - a comparison of large British and German pharmaceutical companies, Technovation 18 (10), 593-604. 
Baldini N., Grimaldi R., Sobrero M., 2006. Institutional changes and the commercialization of academic knowledge: A study of Italian universities' patenting activities between 1965 and 2002, Research Policy, $35(4), 518-532$.

Beaudry C., Schiffauerova A., 2011. Impacts of collaboration and network indicators on patent quality: The case of Canadian nanotechnology innovation, European Management Journal, Volume 29, Issue 5, Pages 362-376.

Bozeman, B., Laredo, P., Mangematin, V., 2007. Understanding the emergence and deployment of "nano" S\&T, Research Policy, 36 (6), 807-812

Braun, T., Schubert, A., Zsindely, S., 1997. Nanoscience and nanotechnology on the balance. Scientometrics $38,321-325$.

Callon M. and Bell G., 1991. Techno-economic networks and science and technology policy. Working paper for the Technology and Economy Programme for Science, Technology and Industry. OECD, Paris.

Camarinha-Matos, L.M., Afsarmanesh, H., 2006. Collaborative Networks: Value creation in a knowledge society, International Federation for Information Processing IFIP, 207, $26-40$.

Cantwell, J.A., 1993. Corporate technological specialisation in international industries. In: Casson, M., Creedy, J. (Eds.), Industrial Concentration and Economic Inequality. Edward Elgar, Aldershot.

Carlson, B., Stankiewicz R., 1991. On the nature, function and composition of technological systems, Journal of Evolutionary Economics, Issue 1, 93-118.

Cheng A., 2012. Exploring the relationship between technology diffusion and new material diffusion: the example of advanced ceramic powders, Technovation, Volume 32, Issues 3-4, Pages 163-167.

Collins K. M. T., Onwuegbuzie A. J., Jiao Q. G., 2007. A mixed methods investigation of mixed methods sampling designs in social and health science research. Journal of Mixed Methods Research, 1, 267-294.

Cooke P., Morgan K., 1994. The Creative Milieu: a Regional Perspective on Innovation, in M. Dodgson, et.al., The Handbook of Industrial Innovation, 57-89.

Cooke P., Morgan K., 1998. The Associational Economy: Firms, Regions and Innovation, Oxford University Press, Oxford.

Cunningham S. W., 2011. Bibliometric discovery of innovation and commercialization pathways in nanotechnology. Technology Management in the Energy Smart World, 1-11.

Doloreux D., 2002. What we should know about regional systems of innovation, Technology in Society, 24 (3), 243-263.

Encaoua D., Guellec D., Martínez C., 2006. Patent systems for encouraging innovation: Lessons from economic analysis, Research Policy, 35 (9), 1423-1440. 
Ernst H., Conley J. G., Omland N., 2012. How to create commercial value from patents: The role of patent management, Research Policy (forthcoming).

ETC Group, 2005. Nanotech's "Second Nature" Patents: Implications for the Global South. Winnipeg, Manitoba; Action Group on Erosion, Technology and Concentration.

Faber J., Hesen A. B., 2004. Innovation capabilities of European nations: Cross-national analyses of patents and sales of product innovations, Research Policy, 33 (2), 193-207.

Fontana R., Geuna A., Matt M., 2006 Factors affecting university-industry R\&amp;D projects: The importance of searching, screening and signaling. Research Policy, 35 (2), 309-323.

Freeman C., 1995. "The National System of Innovation in Historical Perspective", Cambridge Journal of Economics, 19, 5-24.

Genet C., Errabi K., Gauthier C., 2012. Which model of technology transfer for nanotechnology? A comparison with biotech and microelectronics, Technovation, Volume 32, Issues 3-4, Pages 205-215

Greif S., 1992. Patents and sectors of economy. Connection between the international patent classification and the systematics of the sectors of economy, World Patent Information, 14 (4), 245-249.

Goetze C., 2010. An empirical enquiry into co-patent networks and their stars: The case of cardiac pacemaker technology, Technovation, Volume 30, Issues 7-8, July-August 2010, Pages 436-446.

Grimaldi R., Kenney M., Siegel D. S., Wright M., 2011. 30 years after Bayh-Dole: Reassessing academic entrepreneurship, Research Policy, 40 (8), 1045-1057.

Guan J., Chen K., 2012. Modeling the relative efficiency of national innovation systems, Research Policy, 41 (1), 102-115.

Guan J., Chen Z., 2012. Patent collaboration and international knowledge flow, Information Processing \&amp; Management, 48 (1), 170-181.

Guan J., Zhao Q., 2012. The impact of university-industry collaboration networks on innovation in nanobiopharmaceuticals, Technological Forecasting and Social Change.

Hidalgo A., Molero J., Penas G., 2010. Technology and industrialization at the take-off of the Spanish economy: New evidence based on patents, World Patent Information, 32 (1), 53-61.

Huang Z., Chen H., Yip A., Ng G., Guo F., Chen Z., Roco M. C., 2003. Longitudinal patent analysis for nanoscale science and engineering: Country, institution and technology field. Journal of Nanoparticle Research. 5 (3-4), 333-363.

Huang, Can, Ad Notten \& Nico Rasters, 2011, Nanoscience and Technology Publications and Patents: A Review of Social Science Studies and Search Strategies, Journal of Technology Transfer, 36, 2, 145-172 
Islam N., Miyazaki K., 2009. Nanotechnology innovation system: Understanding hidden dynamics of nanoscience fusion trajectories, Technological Forecasting and Social Change, 76 (1), 128-140.

Islam N., Miyazaki K., 2010. An empirical analysis of nanotechnology research domains. Technovation. 30 (4), 229-237.

Johnson A., 1998. Functions in innovation system approaches, Department of Industrial Dynamics, Chalmers University of Technology, Mimeo.

Kang K., Park H., 2012. Influence of government R\&D support and inter-firm collaborations on innovation in Korean biotechnology SMEs, Technovation, 32 (1), 68-78.

Kostoff R. N., Koytcheff R. G., Lau C. G. Y., 2007. Global nanotechnology research literature overview, Technological Forecasting and Social Change, 74 (9), 1733-1747.

Kostoff R. N., Stump J. A., Johnson D., Murday J. S., Lau C. G. Y., Tolles W. M.., 2006. The structure and infrastructure of the global nanotechnology literature. Journal of Nanoparticle Research. 8 (3), 301-321.

Kronz H., Grevink H., 1980. Patent statistics as indicators of technological and commercial trends in the member States of the European Communities (EEC), World Patent Information, 2(1), 4-12.

Lee S., Yoon B., Lee C., Park J., 2009. Business planning based on technological capabilities: Patent analysis for technology-driven roadmapping, Technological Forecasting and Social Change, Volume 76, Pages 769-786.

Leydesdorff, L., Meyer, M., 2003. The Triple Helix of university - industry - government relations. Scientometrics, 58 (2), 191-203.

Linton, J., Walsh, S., 2008. Acceleration and extension of opportunity recognition for nanotechnologies and other emerging technologies. International Small Business Journal. 26(1), 83-99.

Liu X., White S., 2001. Comparing innovation systems: a framework and application to China's transitional context, Research Policy, 30(7), 1091-1114.

Lundvall, B., 1992. National Systems of Innovation: Towards a Theory of Innovation and Interactive Learning, London, Pinter.

Ma Z., Lee Y., Chen C. P., 2009. Booming or emerging? China's technological capability and international collaboration in patent activities, Technological Forecasting and Social Change, 76(6), 787-796.

Malerba F., 2004. Sectoral Systems of Innovation: Concepts, Issues and Analyses of Six Major Sectors in Europe. Cambridge University press.

Meyer M., 2001. Patent Citation Analysis in a Novel Field of Technology: An Exploration of Nano-Science and Nano-Technology. Scientometrics, 51(1), 163-183. 
Miyazaki K., Islam N., 2007. Nanotechnology Systems of Innovation - An Analysis of Industry and Academia Research Activities. Technovation, 27, 661-675.

Miyazaki, K., 1995. Building Competences in the Firm lessons from Japanese and European Optoelectronics. Macmillan, London.

Mogoutov, A., Kahane, B., 2007. Data search strategy for science and technology emergence: A scalable and evolutionary query for nanotechnology tracking. Research Policy, 36, 893-903.

Motohashi K., Muramatsu S., 2012. Examining the university industry collaboration policy in Japan: Patent analysis, Technology in Society, 34 (2), 149-162.

Nelson A. J, 2009. Measuring knowledge spillovers: What patents, licenses and publications reveal about innovation diffusion, Research Policy, 38 (6), 994-1005.

Nelson, R., 1993. National Innovation Systems, Oxford University Press, Oxford.

Nikulainen T., Palmberg C., 2010. Transferring science-based technologies to industry-Does nanotechnology make a difference? Technovation, 30 (1), 3-11.

OECD, 2004. Patents and Innovation: Trends and Policy Challenges. Available on: http://www.oecd.org/dataoecd/48/12/24508541.pdf

OECD, 1997. National Innovation System, Paris: OECD

Patel, P., Pavitt, K., 1997. The technological competencies of the world's largest firms: complex and pathdependent, but not much variety. Research Policy 26, 141-156.

Petruzzelli, A., 2011. The impact of technological relatedness, prior ties, and geographical distance on university-industry collaborations: a joint patent analysis. Technovation. 31, 309-319.

Porter A. L., Cunningham S. W., 2005. Tech mining: exploiting new technologies for competitive advantage. John Wiley and Sons. New Jersey.

Porter, A. L., Youtie, J., Shapira, P., Schoeneck, D. J., 2008. Refining search terms for nanotechnology. Journal of Nanoparticle Research. 10(5), 715-728. Springer. Netherlands.

Roper S., Du J., Love J. H., 2008. Modelling the innovation value chain, Research Policy, 37(6-7), 961-977.

Scheu, M., Veefkind, V., Verbandt, Y., Galan, E., Absalom, R., Förster, W., 2006. Mapping nanotechnology patents: The EPO approach. World Patent Information. 28(3), 204-211.

Shapira P., Youtie J., Kay L., 2011. National innovation systems and the globalization of nanotechnology innovation. The Journal of Technology Transfer. 36, 587-604.

Suzuki J., 2011. Structural modeling of the value of patent, Research Policy, 40 (7), 986-1000.

Tashakkori, A., Teddlie, C., 2007. Mixed Methods in Social and Behavioural Research, Sage Publications 
Inc.

Trappey C. V., Wu H., Taghaboni-Dutta F., Trappey A. J. C., 2011. Using patent data for technology forecasting: China RFID patent analysis, Advanced Engineering Informatics, 25 (1), 53-64.

Tseng F., Hsieh C., Peng Y., Chu Y., 2011. Using patent data to analyze trends and the technological strategies of the amorphous silicon thin-film solar cell industry, Technological Forecasting and Social Change, 78 (2), 332-345.

WIPO, 2011. Economics and Statistics Division, World Intellectual Property Indicators. Available on: http://www.wipo.int/ipstats/en/statistics/patents/

Wu Y. J., Lee P., 2007. The use of patent analysis in assessing ITS innovations: US, Europe and Japan, Transportation Research Part A: Policy and Practice, 41 (6), 568-586.

Yim, D. S., Kang, B., 2008. Policy Options for Establishing Effective Subnational Innovation Systems and Technological Capacity-building, Asia-Pacific Trade and Investment Review, Issue 4, 115-137. 
Table 1: The outline of research design

\begin{tabular}{|c|c|}
\hline $\begin{array}{l}\text { Patent database } \\
\text { selection }\end{array}$ & $\begin{array}{l}\text { - } \quad \text { Searching for available patent database providers } \\
\text { - } \quad \text { Comparison of patent database providers } \\
\text { - } \quad \text { Selecting the patent database provider and developing a taxonomy }\end{array}$ \\
\hline Patent search & $\begin{array}{l}\text { - } \quad \text { Analysis of patent search strategies } \\
\text { - } \quad \text { Gathering the right patent classification codes for nanotechnology } \\
\text { - } \quad \text { Eliminating duplicates by obtaining patent data with DWPI } \\
\text { - } \quad \text { Exporting data with TDA format }\end{array}$ \\
\hline $\begin{array}{l}\text { Patent data } \\
\text { optimization }\end{array}$ & $\begin{array}{ll}\text { - } & \text { Loading required fields of patent data to TDA } \\
\text { - } & \text { Filtering results to eliminate duplicates } \\
\text { - } & \text { Preparing categories and groups for analysis }\end{array}$ \\
\hline Patent data analysis & $\begin{array}{l}\text { - } \quad \text { Analysis of nanotechnology patent data } \\
\text { - } \quad \text { Mapping the technological dynamics, competencies and linkages } \\
\text { - } \quad \text { Comparative analysis of nanotechnology sub-categories }\end{array}$ \\
\hline $\begin{array}{l}\text { Findings and } \\
\text { conclusion }\end{array}$ & $\begin{array}{l}\text { - Interpreting the patent analysis of technology trends, linkages and competencies } \\
\text { - Implications and Recommendations }\end{array}$ \\
\hline
\end{tabular}

Table 2: Number of collaborations between organisations

\begin{tabular}{cccc} 
& Government & Academic & Inventor \\
\hline Corporate & 163 & 1784 & 6850 \\
Inventor & 406 & 2050 & \\
Academic & 194 & & \\
\hline
\end{tabular}

Table 3: Patent share of actors in their respective countries

\begin{tabular}{|c|c|c|c|c|c|c|c|c|c|c|}
\hline & Number of patents & 25570 & 17168 & 5614 & 4648 & 2447 & 1243 & 1234 & 975 & 857 \\
\hline Number of patents & Countries & US & $J P$ & KR & $\mathrm{CN}$ & $\mathrm{DE}$ & $\mathrm{RU}$ & FR & GB & TW \\
\hline 36351 & Corporate & 16599 & 14591 & 3005 & 973 & 1803 & 287 & 601 & 721 & 299 \\
\hline 20097 & Academic & 8505 & 3730 & 2911 & 3175 & 548 & 725 & 612 & 274 & 520 \\
\hline 4657 & Inventors & 2451 & 255 & 232 & 1027 & 214 & 231 & 31 & 41 & 59 \\
\hline
\end{tabular}

Table 4: Patent share of actors for each technology field

\begin{tabular}{|l|l|l|l|l|l|l|l|l|l|l|l|}
\hline & Number of patents & 25714 & 22451 & 17959 & 13328 & 12923 & 12352 & 10235 & 9884 & 8027 & 7739 \\
\hline $\begin{array}{l}\text { Number of } \\
\text { patents }\end{array}$ & Actors Countries & $\mathrm{L}$ & $\mathrm{U}$ & $\mathrm{A}$ & $\mathrm{V}$ & $\mathrm{E}$ & $\mathrm{P}$ & $\mathrm{B}$ & $\mathrm{S}$ & $\mathrm{D}$ & $\mathrm{X}$ \\
\hline 36351 & Corporate & 17568 & 15584 & 11278 & 9911 & 7567 & 8254 & 4887 & 5915 & 4447 & 5087 \\
\hline 20097 & Academic & 8588 & 7065 & 6590 & 3731 & 5582 & 3763 & 4095 & 4122 & 3275 & 2771 \\
\hline 4657 & Inventors & 1371 & 1166 & 1155 & 712 & 695 & 1141 & 1816 & 771 & 745 & 476 \\
\hline
\end{tabular}


Table 5: Leading nanotechnology patent holders and their linkages

\begin{tabular}{|c|c|c|c|c|c|c|c|}
\hline $\begin{array}{l}\text { Number } \\
\text { of } \\
\text { Records }\end{array}$ & Inventor & $\begin{array}{l}\text { Top } \\
\text { Organization }\end{array}$ & Top-3 Collaborators & $\begin{array}{l}\text { Year } \\
\text { Range }\end{array}$ & $\begin{array}{l}\text { Percentag } \\
\text { e of } \\
\text { Records in } \\
\text { Last-3 } \\
\text { Years }\end{array}$ & $\begin{array}{l}\text { Top Technology } \\
\text { Terms }\end{array}$ & $\begin{array}{l}\text { Top } \\
\text { Countries }\end{array}$ \\
\hline 908 & $\begin{array}{l}\text { Yang } \\
\text { Mengjun }\end{array}$ & YANG M [908] & None & $2000-2001$ & ०\% of 908 & $\begin{array}{l}\mathrm{Bo4}-\mathrm{A} 10[846] ; \\
\mathrm{Bo} 4-\mathrm{A} 08[784] ; \\
\text { Bo4-Aog }[726]\end{array}$ & CN [908] \\
\hline 398 & $\begin{array}{l}\text { Fan Shou } \\
\text { Shan }\end{array}$ & $\begin{array}{l}\text { HON HAI } \\
\text { PRECISION IND } \\
\text { CO LTD [397] }\end{array}$ & $\begin{array}{l}\text { Jiang Kai Li [271]; } \\
\text { Liu Liang [161]; } \\
\text { Liu Chang Hong [84] }\end{array}$ & $2002-2010$ & $28 \%$ of 398 & $\begin{array}{l}\text { E05-Uo3 [101]; } \\
\text { Lo3-Ao2B [87]; } \\
\text { Lo3-Ao2G [85] }\end{array}$ & $\begin{array}{l}\text { CN }[311] ; \\
\text { US }[271] ; \\
\text { TW }[88]\end{array}$ \\
\hline 284 & Jiang Kai Li & $\begin{array}{l}\text { HON HAI } \\
\text { PRECISION IND } \\
\text { CO LTD [283] }\end{array}$ & $\begin{array}{l}\text { Fan Shou Shan }[271] ; \\
\text { Liu Liang }[116] ; \\
\text { Chen Feng }[78]\end{array}$ & $2002-2010$ & $28 \%$ of 284 & $\begin{array}{l}\text { E05-Uo3 [82]; } \\
\text { Lo3-Ao2G [63]; } \\
\text { Lo3-Ao2B [61] }\end{array}$ & $\begin{array}{l}\text { CN }[209] ; \\
\text { US }[182] ; \\
\text { TW }[74]\end{array}$ \\
\hline 245 & Liu Liang & $\begin{array}{l}\text { HON HAI } \\
\text { PRECISION IND } \\
\text { CO LTD [204] } \\
\end{array}$ & $\begin{array}{l}\text { Fan Shou Shan }[161] ; \\
\text { Jiang Kai Li }[116] ; \\
\text { Chen Feng }[63]\end{array}$ & $2002-2010$ & $34 \%$ of 245 & $\begin{array}{l}\text { Lo3-Ao2B [50]; } \\
\text { Lo3-Ao2G [47]; } \\
\text { E05-Uo3 [41] }\end{array}$ & $\begin{array}{l}\text { CN [213]; } \\
\text { US [182]; } \\
\text { TW [31] }\end{array}$ \\
\hline 139 & $\begin{array}{l}\text { Bando } \\
\text { Yoshio }\end{array}$ & $\begin{array}{l}\text { DOKURITSU } \\
\text { GYOSEI HOJIN } \\
\text { BUSSHITSU } \\
\text { ZAIRYO }[136] \\
\end{array}$ & $\begin{array}{l}\text { Dmitri Golberg [42]; } \\
\text { Chengchun Tang [32]; } \\
\text { Demitry Golberg [17] }\end{array}$ & $1997-2009$ & $6 \%$ of 139 & $\begin{array}{l}\mathrm{E}_{31-\mathrm{O}_{3}[44] ;} \\
\text { U12-Bo3F2 [30]; } \\
\text { U11-Co1J6 [28] }\end{array}$ & $\begin{array}{l}\text { JP }[138] ; \\
\text { WO [6] }\end{array}$ \\
\hline 124 & $\begin{array}{l}\text { Rueckes } \\
\text { Thomas }\end{array}$ & $\begin{array}{l}\text { NANTERO INC } \\
{[118]}\end{array}$ & $\begin{array}{l}\text { Segal Brent M. [70]; } \\
\text { Bertin Claude L. [56]; } \\
\text { Sivarajan Ramesh [24] }\end{array}$ & $1999-2010$ & $4 \%$ of 124 & $\begin{array}{l}\mathrm{U}_{12}-\mathrm{B}_{3} \mathrm{~F}_{2} \mathrm{~A}[33] ; \\
\mathrm{U}_{14}-\mathrm{A}_{3} \mathrm{X}[26] ; \\
\mathrm{U}_{11-\mathrm{C}_{18} \mathrm{~B}_{5}[24]}\end{array}$ & $\begin{array}{l}\text { US }[121] ; \\
\text { WO [25] }\end{array}$ \\
\hline 118 & Chen Feng & $\begin{array}{l}\text { HON HAI } \\
\text { PRECISION IND } \\
\text { COLTD [8o] }\end{array}$ & $\begin{array}{l}\text { Fan Shou Shan }[78] ; \\
\text { Jiang Kai Li }[78] ; \\
\text { Liu Liang }[63]\end{array}$ & $2007-2010$ & $45 \%$ of 118 & $\begin{array}{l}\text { E05-U03 [35]; } \\
\text { Lo3-Ao2B [18]; } \\
\text { Lo3-Ao2G [18] }\end{array}$ & $\begin{array}{l}\text { CN [90]; } \\
\text { US [77]; } \\
\text { TW [28] }\end{array}$ \\
\hline 101 & $\begin{array}{l}\text { Mirkin } \\
\text { Chad A. }\end{array}$ & $\begin{array}{l}\text { UNIV } \\
\text { NORTHWESTER } \\
\text { N [68] }\end{array}$ & $\begin{array}{l}\text { Elghanian Robert [31]; } \\
\text { Storhoff James J. [31]; } \\
\text { Carlson Robert M. [30]; } \\
\text { Letsinger Robert L. [30] }\end{array}$ & $1993-2010$ & $11 \%$ of 101 & $\begin{array}{l}\text { Do5-Hog [49]; } \\
\text { Bo4-Eo1 [45]; } \\
\text { B12-Ko4F [39] }\end{array}$ & $\begin{array}{l}\text { US [101]; } \\
\text { WO [81] }\end{array}$ \\
\hline 100 & $\begin{array}{l}\text { lijima } \\
\text { Sumio }\end{array}$ & NEC CORP [75] & $\begin{array}{l}\text { Yudasaka Masako [70]; } \\
\text { Kasuya Daisuke }[16] ; \\
\text { Yoshitake Tsutomu [14] }\end{array}$ & $1992-2009$ & $1 \%$ of 100 & $\begin{array}{l}\text { E05-Uo3 [30]; } \\
\text { Eo5-Uo2 [26]; } \\
\text { Lo2-Ho4B [26] }\end{array}$ & $\begin{array}{l}\text { JP }[100] ; \\
\text { WO [56] }\end{array}$ \\
\hline 91 & $\begin{array}{l}\text { Liu Chang } \\
\text { Hong }\end{array}$ & $\begin{array}{l}\text { HON HAI } \\
\text { PRECISION IND } \\
\text { CO LTD [91] } \\
\end{array}$ & $\begin{array}{l}\text { Fan Shou Shan }[84] ; \\
\text { Jiang Kai Li }[36] ; \\
\text { Wang Ding }[24]\end{array}$ & $2004-2010$ & $26 \%$ of 91 & $\begin{array}{l}\text { E05-Uo3 [35]; } \\
\text { A12-W14 [20]; } \\
\text { Lo3-Ao2B [20] }\end{array}$ & $\begin{array}{l}\text { CN }[58] ; \\
\text { US [50]; } \\
\text { TW [33] }\end{array}$ \\
\hline 88 & $\begin{array}{l}\text { Nakayama } \\
\text { Yoshikazu }\end{array}$ & $\begin{array}{l}\text { NAKAYAMA Y } \\
\text { [48] }\end{array}$ & $\begin{array}{l}\text { Harada Akio [29]; } \\
\text { Akita Seiji [23]; } \\
\text { Nagasaka Takeshi [13] }\end{array}$ & $1998-2010$ & $7 \%$ of 88 & $\begin{array}{l}\text { Eo5-Uo3 }[23] ; \\
\text { Jo4-Eo4 }[19] ; \\
\text { Lo2-Ho4B [17] }\end{array}$ & $\begin{array}{l}\text { JP }[85] ; \\
\text { WO [28]; } \\
\text { US [13] }\end{array}$ \\
\hline 84 & $\begin{array}{l}\text { Williams } \\
\text { Richard } \\
\text { Stanley }\end{array}$ & $\begin{array}{l}\text { WILLIAMS R S } \\
\text { [71] }\end{array}$ & $\begin{array}{l}\text { Kuekes Philip John [28]; } \\
\text { Wang Shih Yuan }[16] ; \\
\text { Wu Wei }[14]\end{array}$ & $1997-2010$ & $10 \%$ of 84 & $\begin{array}{l}\mathrm{U}_{12}-\mathrm{B}_{03} \mathrm{~F} 2 \mathrm{~A}[24] ; \\
\text { Eo6-H [8]; } \\
\mathrm{U}_{11-\mathrm{C}_{13}[8] ;} \\
\mathrm{U}_{12}-\mathrm{B}{ }_{3} \mathrm{~F} 2 \mathrm{~B}[8] ; \\
\mathrm{U}_{12-\mathrm{Q}}[8]\end{array}$ & $\begin{array}{l}\text { US [78]; } \\
\text { WO [9] }\end{array}$ \\
\hline 78 & $\begin{array}{l}\text { Segal Brent } \\
\text { M. }\end{array}$ & $\begin{array}{l}\text { NANTERO INC } \\
\text { [77] }\end{array}$ & $\begin{array}{l}\text { Rueckes Thomas [70]; } \\
\text { Bertin Claude L. [31]; } \\
\text { Brock Darren K. [23] }\end{array}$ & $2001-2009$ & $1 \%$ of 78 & $\begin{array}{l}\mathrm{U}_{12-\mathrm{B}_{3} \mathrm{~F} 2 \mathrm{~A}[23]} \\
\mathrm{U}_{14}-\mathrm{A}_{3} \mathrm{X}[19] ; \\
\mathrm{U}_{11}-\mathrm{C}_{18} \mathrm{~B}_{5}[12]\end{array}$ & $\begin{array}{l}\text { US [75]; } \\
\text { WO [22] }\end{array}$ \\
\hline 77 & $\begin{array}{l}\text { Wang Shih } \\
\text { Yuan }\end{array}$ & WANG S [66] & $\begin{array}{l}\text { Wu Wei }[20] ; \\
\text { Williams Richard } \\
\text { Stanley }[16] ; \\
\text { Kobayashi Nobuhiko } \\
{[15]}\end{array}$ & $1989-2010$ & $16 \%$ of 77 & $\begin{array}{l}\mathrm{U}_{12}-\mathrm{B}_{03} \mathrm{~F}_{2} \mathrm{~A}[12] \\
\mathrm{So}_{3}-\mathrm{E}_{4} \mathrm{D}_{1}[8] \\
\mathrm{U}_{11}-\mathrm{C}_{13}[8]\end{array}$ & $\begin{array}{l}\text { US [61]; } \\
\text { WO [17] }\end{array}$ \\
\hline 76 & $\begin{array}{l}\text { Yudasaka } \\
\text { Masako }\end{array}$ & NEC CORP [68] & $\begin{array}{l}\text { lijima Sumio [70]; } \\
\text { Kasuya Daisuke [15]; } \\
\text { Yoshitake Tsutomu [14] }\end{array}$ & $1992-2009$ & $4 \%$ of 76 & $\begin{array}{l}\text { E05-Uo2 [22]; } \\
\text { Eo5-Uo3 [19]; } \\
\text { Lo2-Ho4B [16] }\end{array}$ & $\begin{array}{l}J P[76] ; \\
\text { WO [47] }\end{array}$ \\
\hline 68 & $\begin{array}{l}\text { Bertin } \\
\text { Claude L. }\end{array}$ & $\begin{array}{l}\text { NANTERO INC } \\
{[64]}\end{array}$ & $\begin{array}{l}\text { Rueckes Thomas [56]; } \\
\text { Segal Brent M. [31]; } \\
\text { Meinhold Mitchell [16] }\end{array}$ & $2003-2009$ & $1 \%$ of 68 & $\begin{array}{l}\mathrm{U}_{12}-\mathrm{Bo3}_{2} \mathrm{~A}[16] ; \\
\mathrm{U}_{14}-\mathrm{Ao3}_{3} \mathrm{~B}[16] ; \\
\text { Lo4-E15 }[11]\end{array}$ & $\begin{array}{l}\text { US [68]; } \\
\text { WO [13] }\end{array}$ \\
\hline 68 & $\begin{array}{l}\text { Yadav } \\
\text { Tapesh }\end{array}$ & YADAV T [49] & $\begin{array}{l}\text { Alexander John [14]; } \\
\text { Au Ming [14]; } \\
\text { Dirstine Roger [14]; } \\
\text { Franke Evan [14]; } \\
\text { Miremadi Bijan [14]; }\end{array}$ & $1996-2005$ & $0 \%$ of 68 & $\begin{array}{l}\text { Jo4-E04 }[15] ; \\
\text { Lo3-J }[11] ; \\
\text { Vo4-Xo1B [11] }\end{array}$ & $\begin{array}{l}\text { US [68]; } \\
\text { WO [7] }\end{array}$ \\
\hline
\end{tabular}


Table 6: Emerging technology profile for nanotechnology

\begin{tabular}{|c|c|c|c|c|c|c|}
\hline 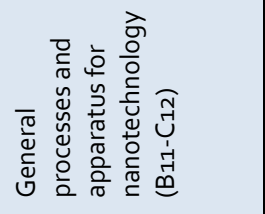 & 足 & \begin{tabular}{l}
\multicolumn{1}{c}{} \\
ஸे \\
1 \\
Lิ \\
Oे
\end{tabular} & 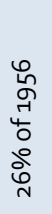 & 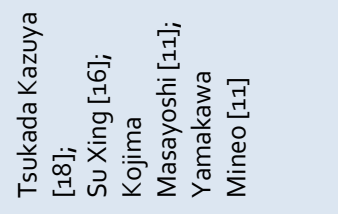 & 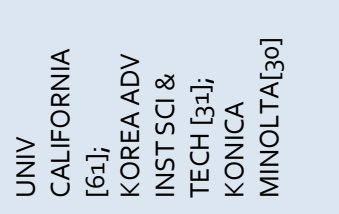 & 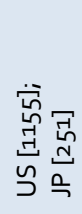 \\
\hline 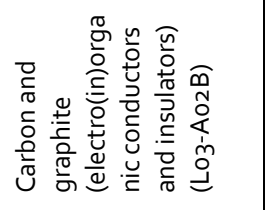 & : & 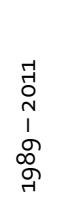 & 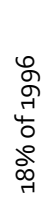 & 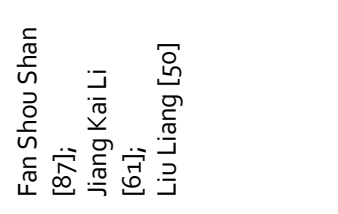 & 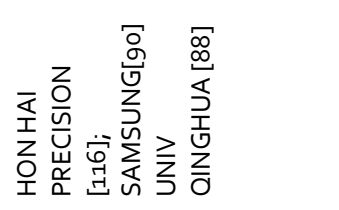 & 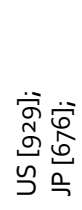 \\
\hline 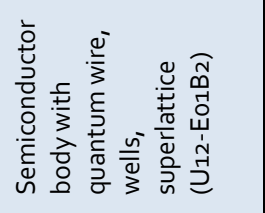 & 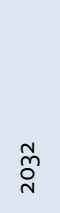 & $\begin{array}{l}7 \\
\stackrel{1}{1} \\
1 \\
1 \\
0 \\
0 \\
9 \\
9 \\
1\end{array}$ & 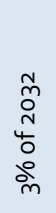 & 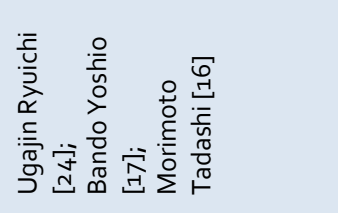 & 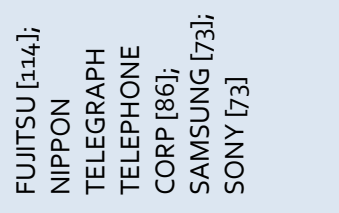 & 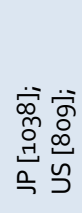 \\
\hline 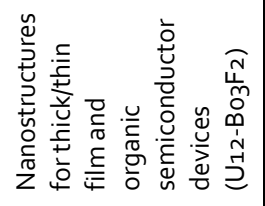 & ণे & $\begin{array}{l}\text { ने } \\
\text { ते } \\
1 \\
\text { oे } \\
\text { Oे }\end{array}$ & 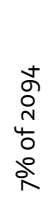 & 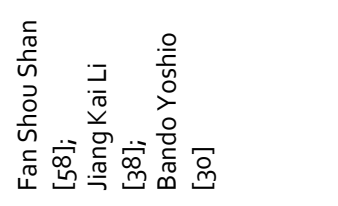 & 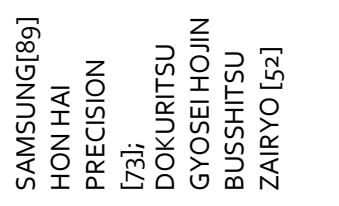 & 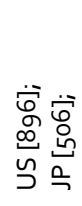 \\
\hline 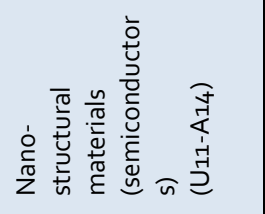 & જે & $\begin{array}{l}-1 \\
\stackrel{2}{2} \\
1 \\
\text { Lે } \\
\text { مे }\end{array}$ & 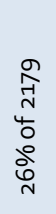 & 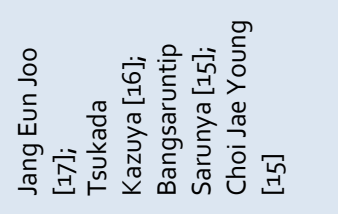 & 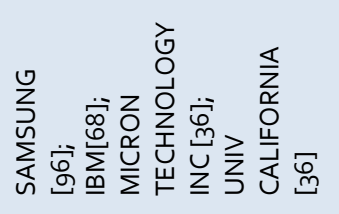 & 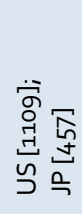 \\
\hline 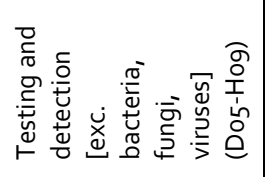 & 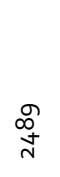 & $\begin{array}{l}-1 \\
\stackrel{1}{1} \\
\text { 1 } \\
0 \\
0 \\
0 \\
9 \\
4\end{array}$ & 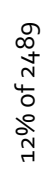 & 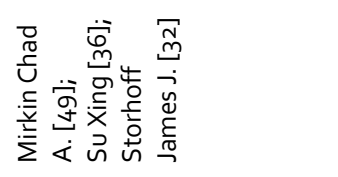 & 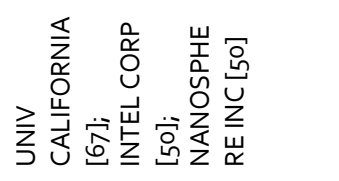 & 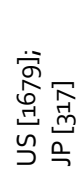 \\
\hline 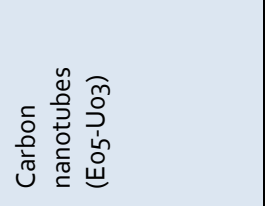 & $\begin{array}{l}\text { ڤ్ } \\
\text { సે }\end{array}$ & $\begin{array}{l}7 \\
\stackrel{1}{1} \\
1 \\
1 \\
\text { مे } \\
\text { - }\end{array}$ & 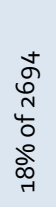 & 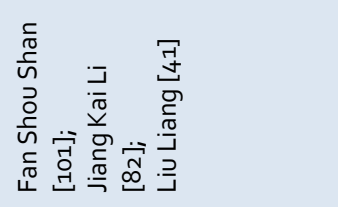 & 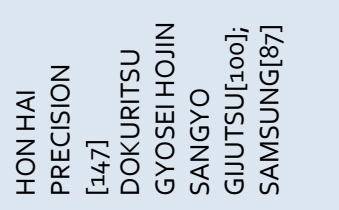 & 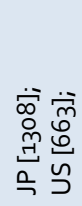 \\
\hline 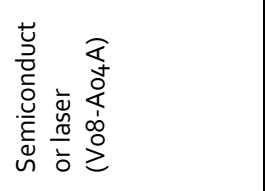 & $\stackrel{\hat{\lambda}}{\hat{N}}$ & 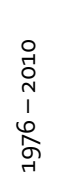 & 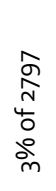 & 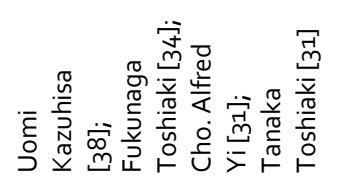 & 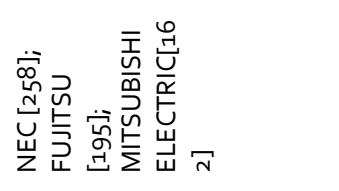 & 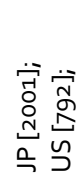 \\
\hline 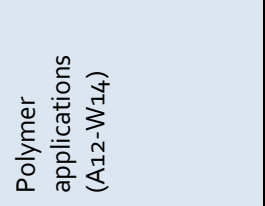 & \begin{tabular}{l}
0 \\
\multirow{+}{0}{} \\
\multirow{+}{*}{}
\end{tabular} & $\begin{array}{l}71 \\
\stackrel{1}{2} \\
1 \\
\text { Ln } \\
\text { Oे }\end{array}$ & 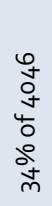 & 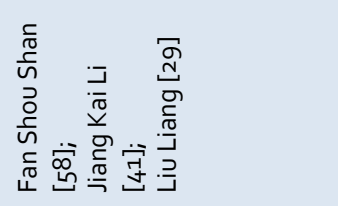 & 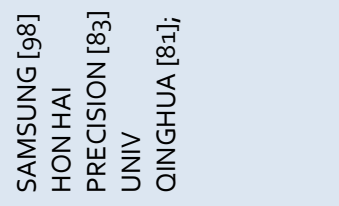 & 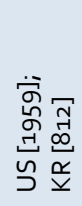 \\
\hline
\end{tabular}



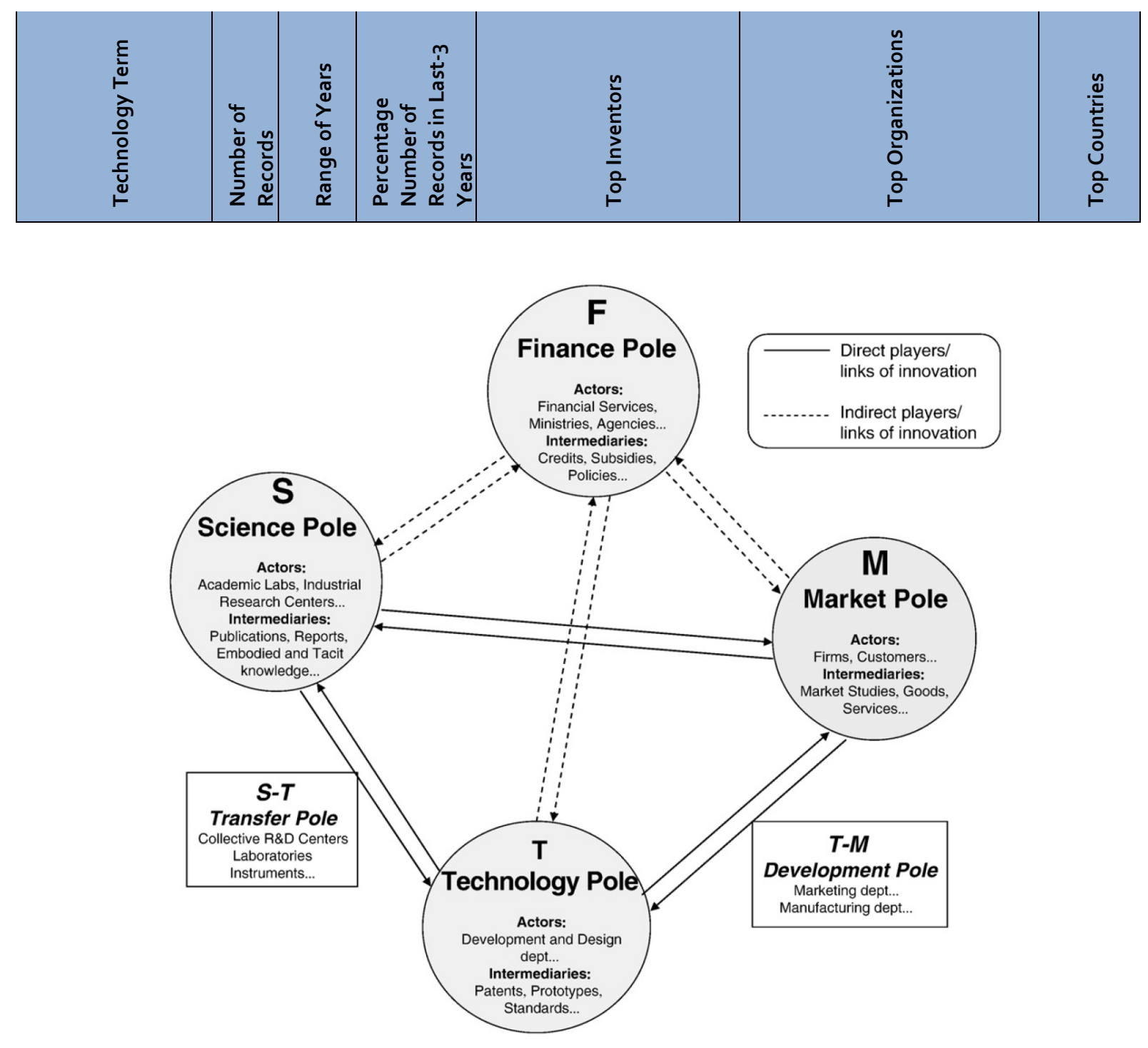

Figure 1: Techno-economic network (TEN) framework (modified from Callon 1991) 


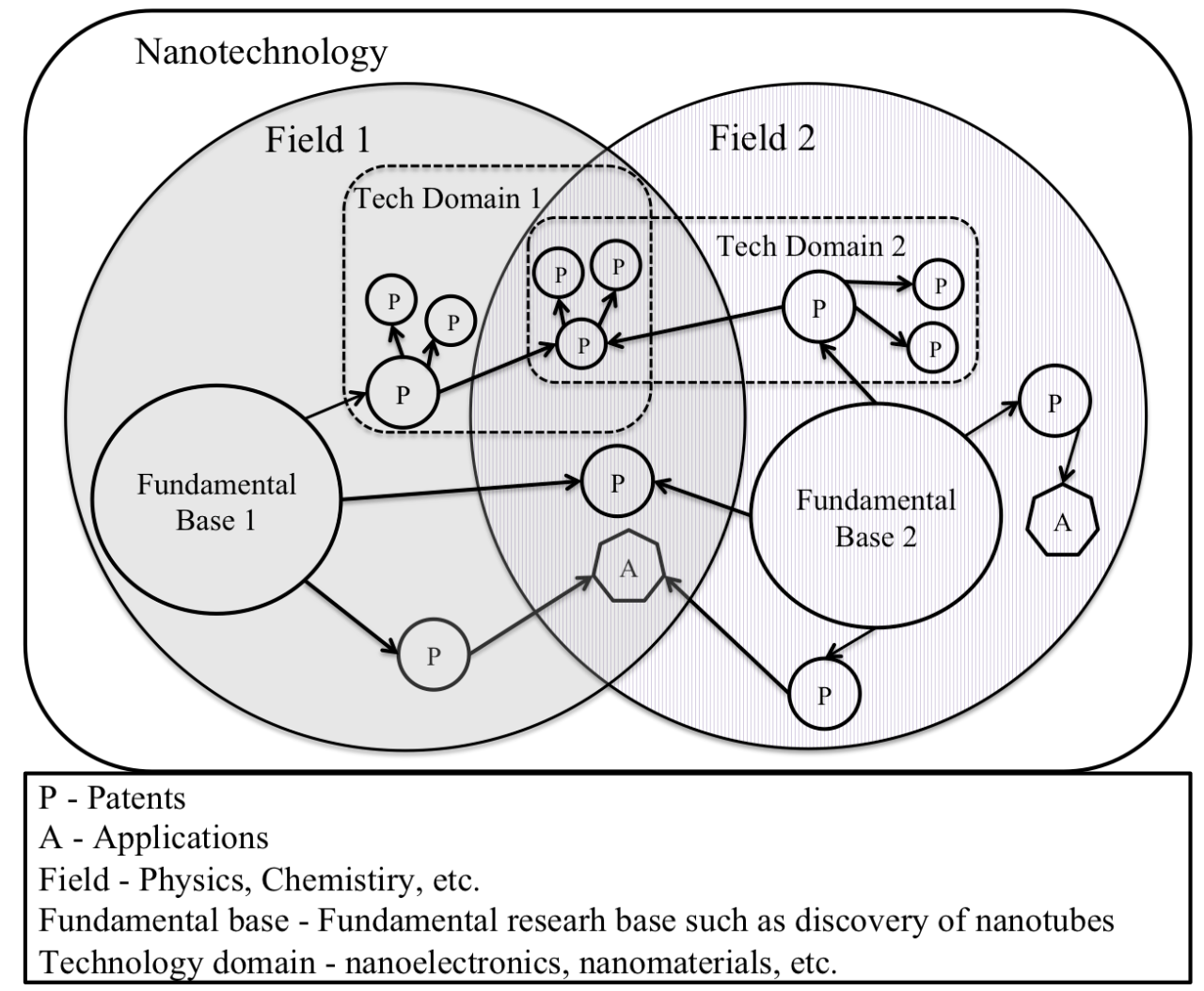

Figure 2: The proposed model for technology linkages

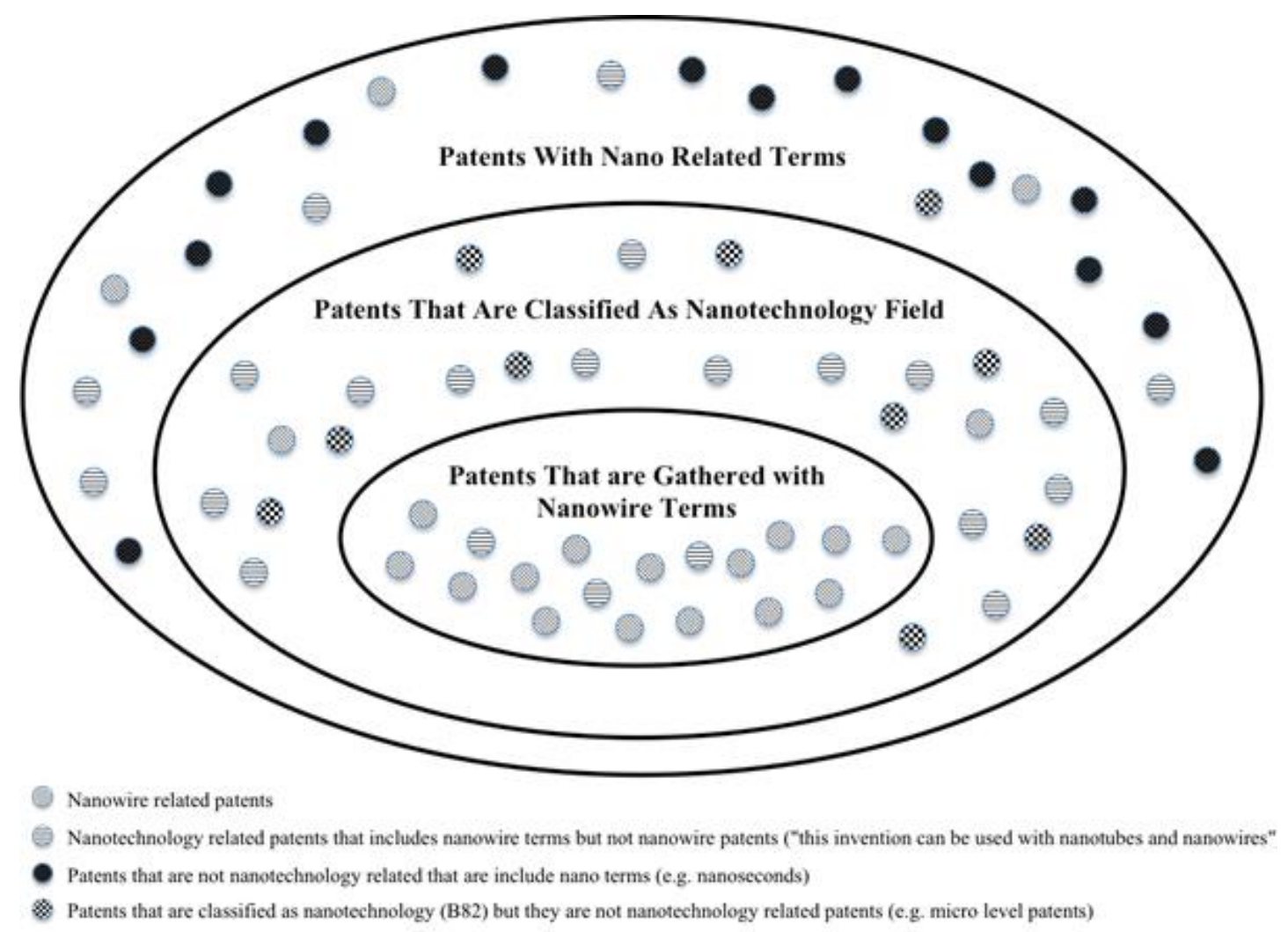

Figure 3: An illustration of patent data gathering method 


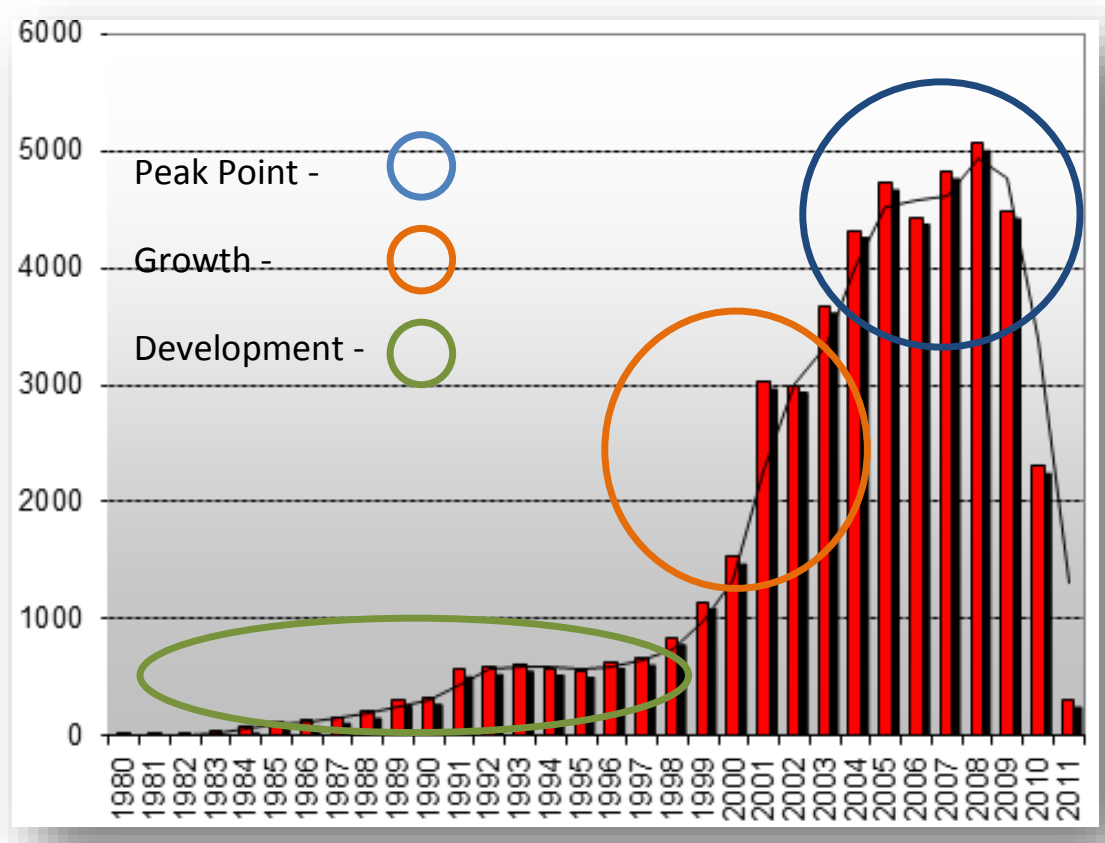

Figure 4: Nanotechnology patenting records per year

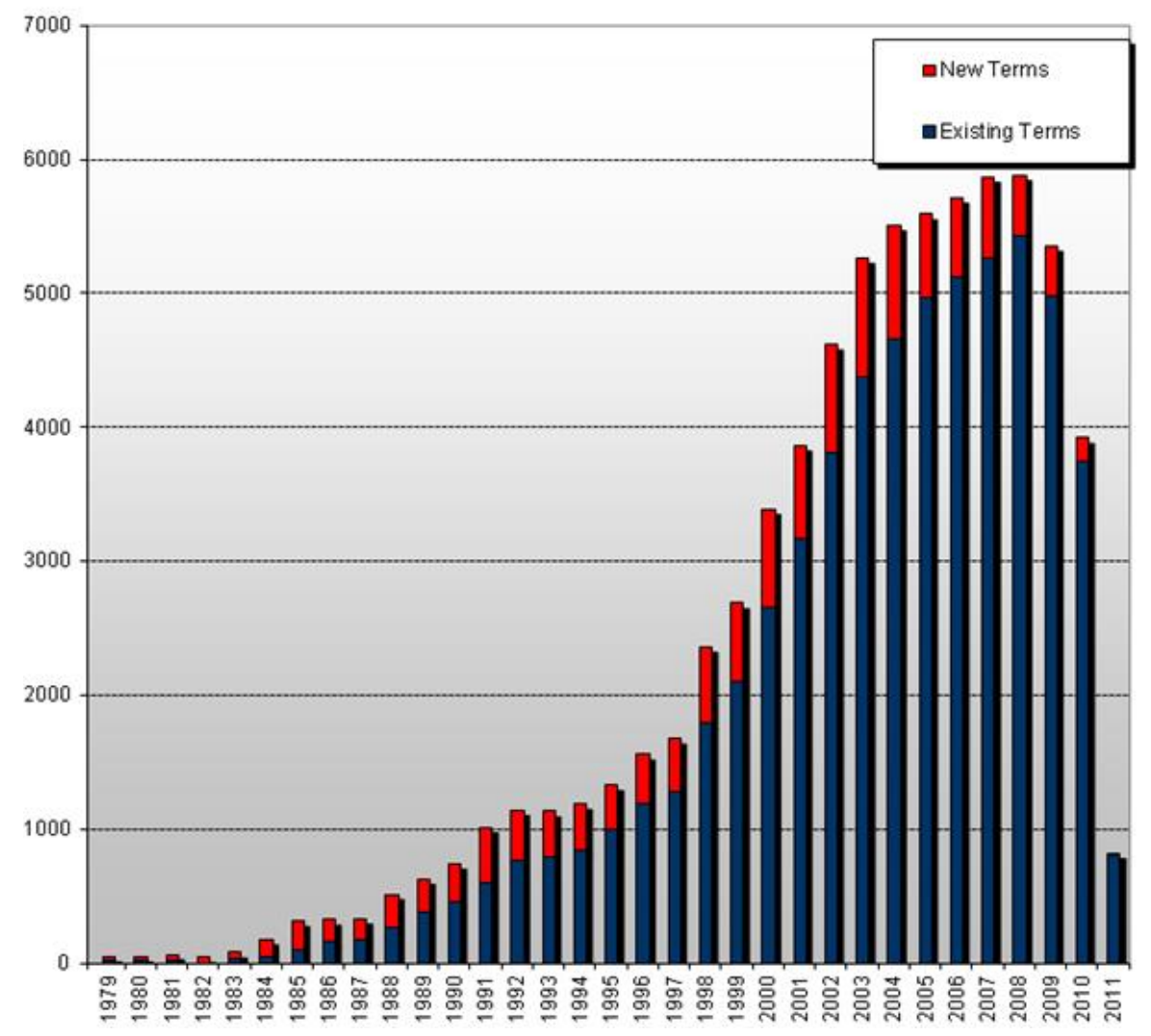

Figure 5: Number of new technology terms per year 


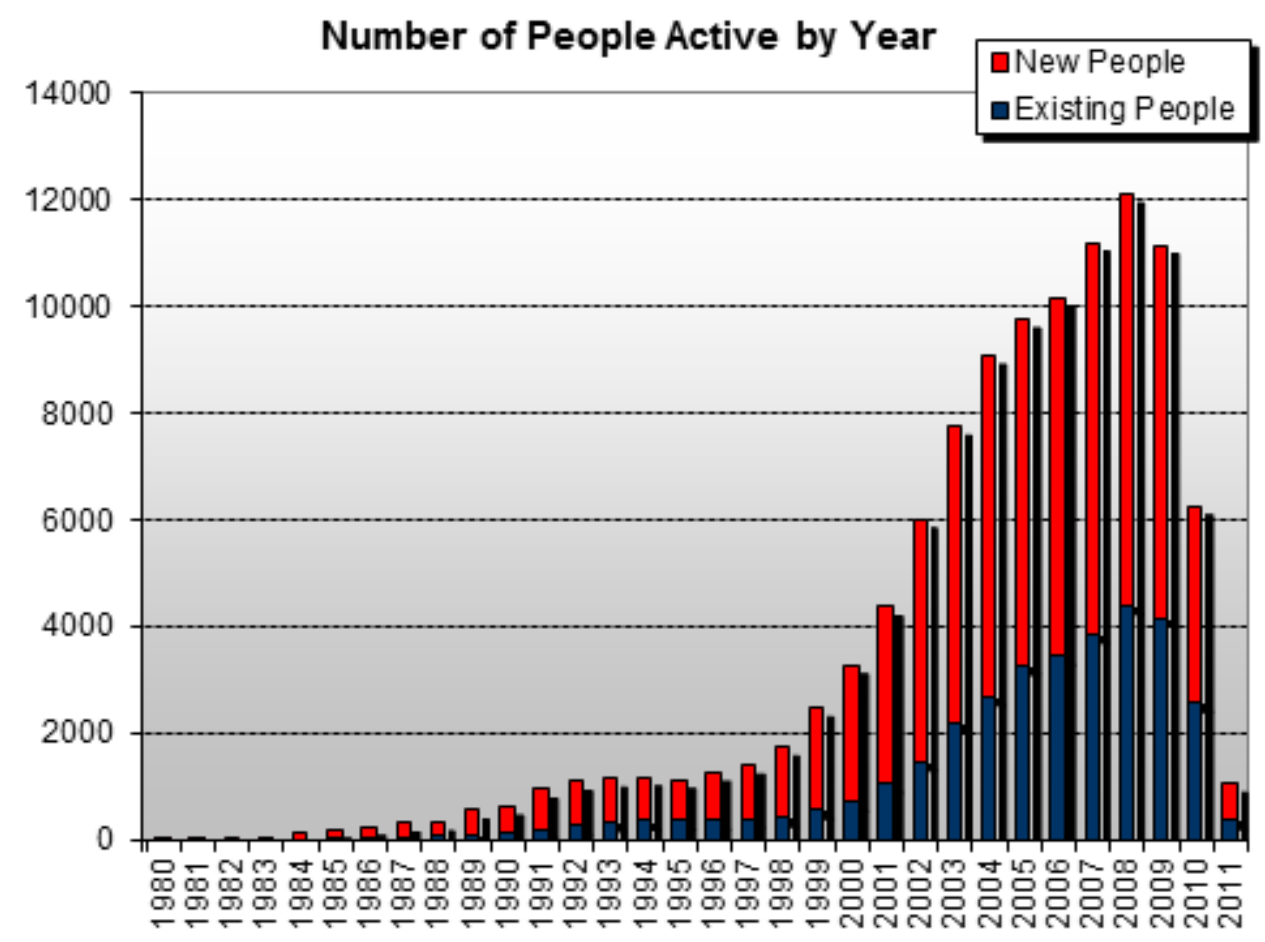

Figure 6: Number of new inventors per year

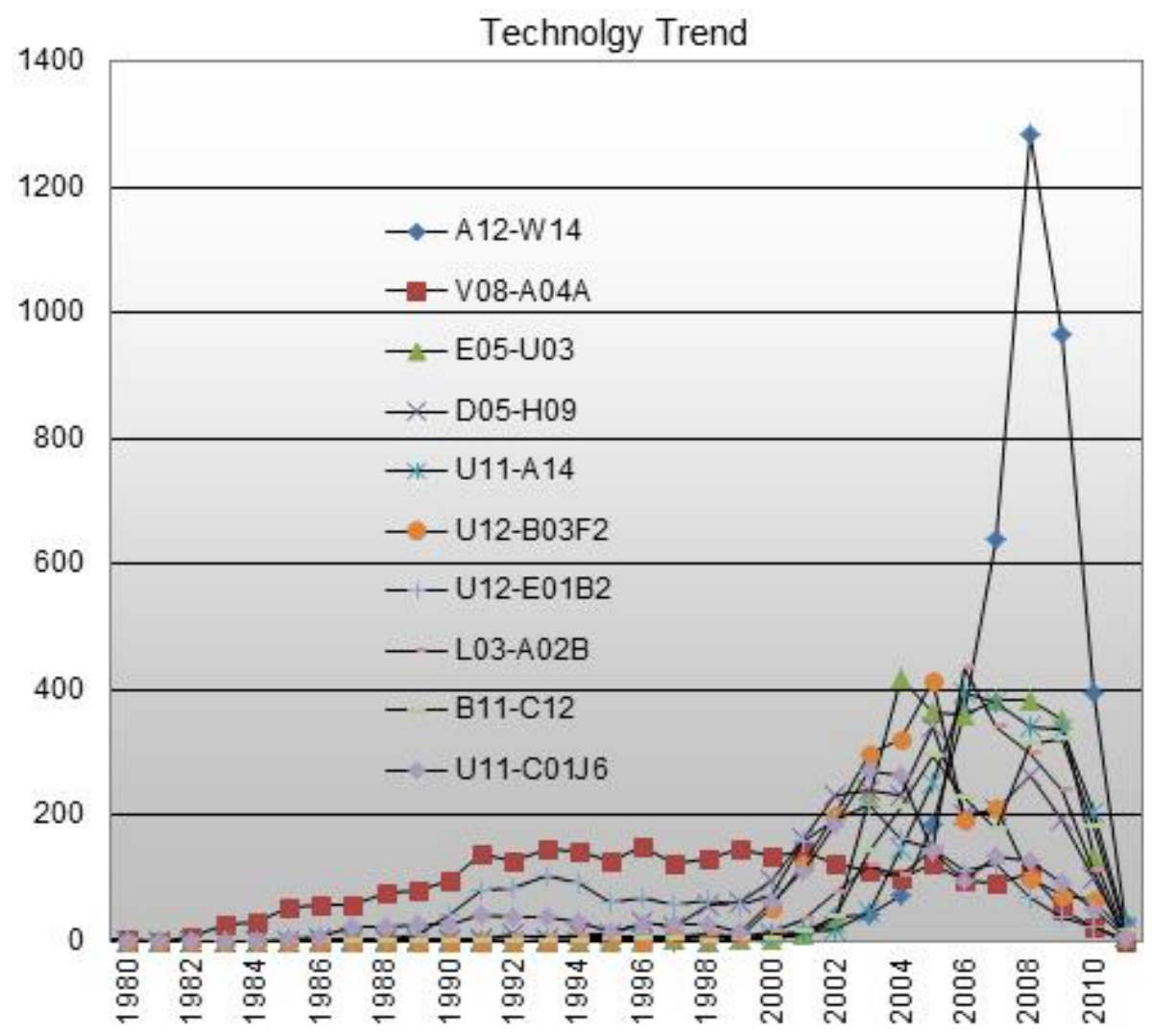

Figure 7: Patented technology trends in nanotechnology 


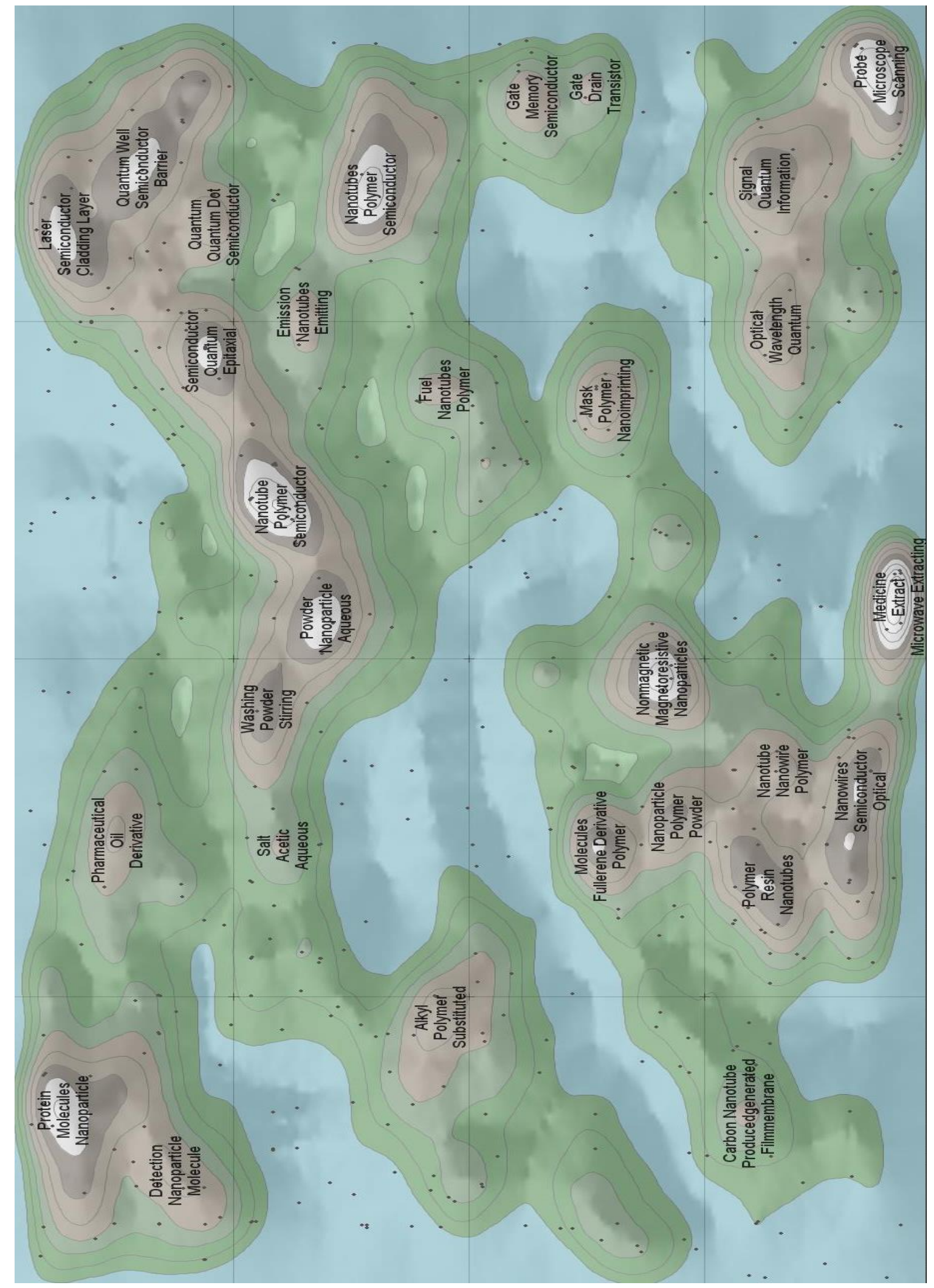

Figure 8: Interrelations of nanotechnolgy fields (Image generated by themescape mapping) 


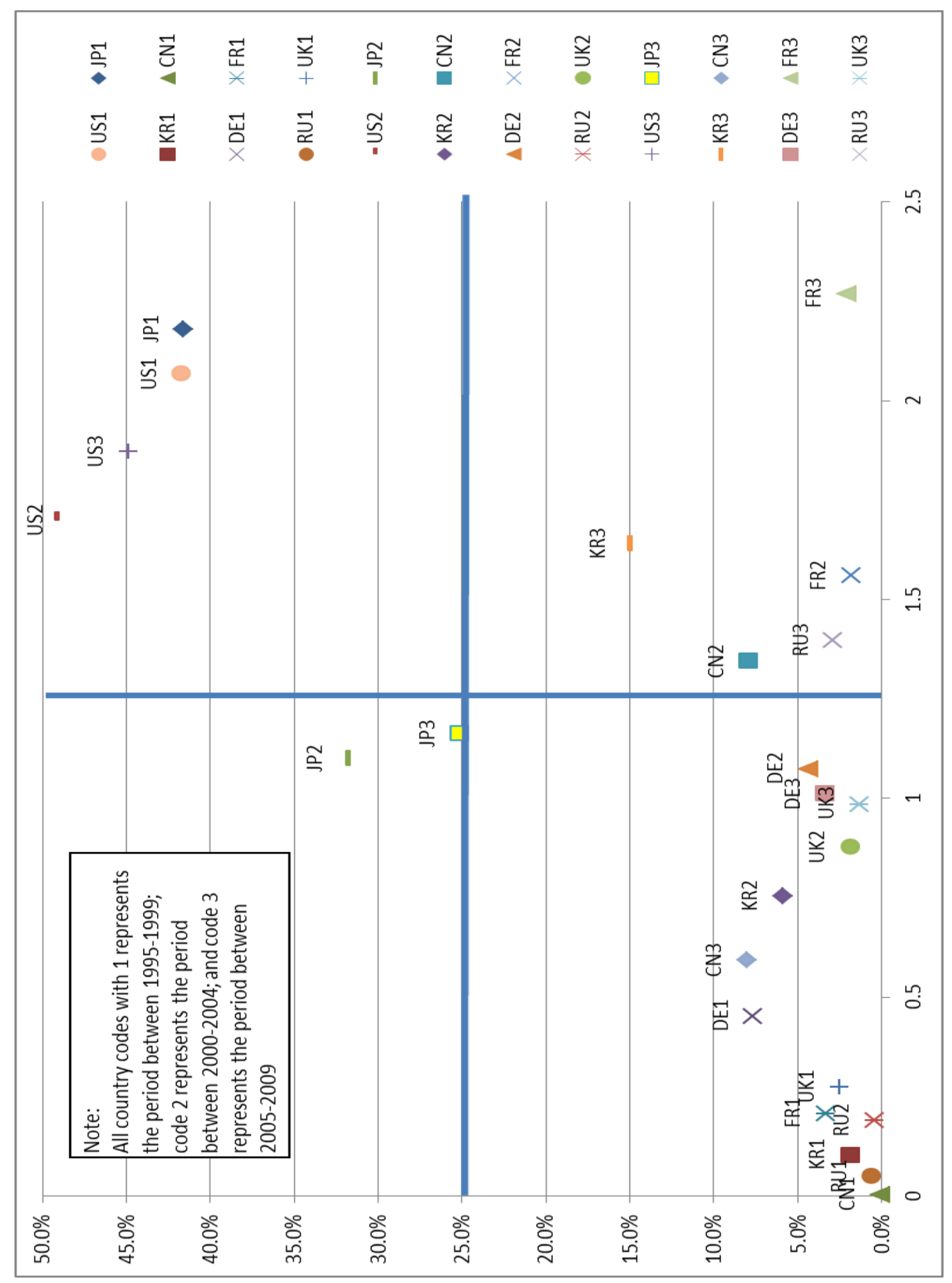

Figure 9: Profile of the nano-technological competencies by regions 